Portland State University

PDXScholar

$11-29-1990$

\title{
Comparison of the Modal Frequency Levels of Nonsmoking and Cigarette Smoking White Females Between the Ages of Forty and Fifty Years
}

Janis Mae Kaufman

Portland State University

Follow this and additional works at: https://pdxscholar.library.pdx.edu/open_access_etds

Part of the Speech and Hearing Science Commons

Let us know how access to this document benefits you.

\section{Recommended Citation}

Kaufman, Janis Mae, "Comparison of the Modal Frequency Levels of Nonsmoking and Cigarette Smoking White Females Between the Ages of Forty and Fifty Years" (1990). Dissertations and Theses. Paper 4175. https://doi.org/10.15760/etd.6059

This Thesis is brought to you for free and open access. It has been accepted for inclusion in Dissertations and Theses by an authorized administrator of PDXScholar. Please contact us if we can make this document more accessible: pdxscholar@pdx.edu. 
AN ABSTRACT OF THE THESIS OF Janis Mae Kaufman for the Master of Science in Speech Communication: Speech and Hearing Sciences presented November 29, 1990.

Title: Comparison of the Modal Frequency Levels of Nonsmoking and Cigarette Smoking White Females Between the Ages of Forty and Fifty Years

APPROVED BY MEMBERS OF THE THESIS COMMITTEE:

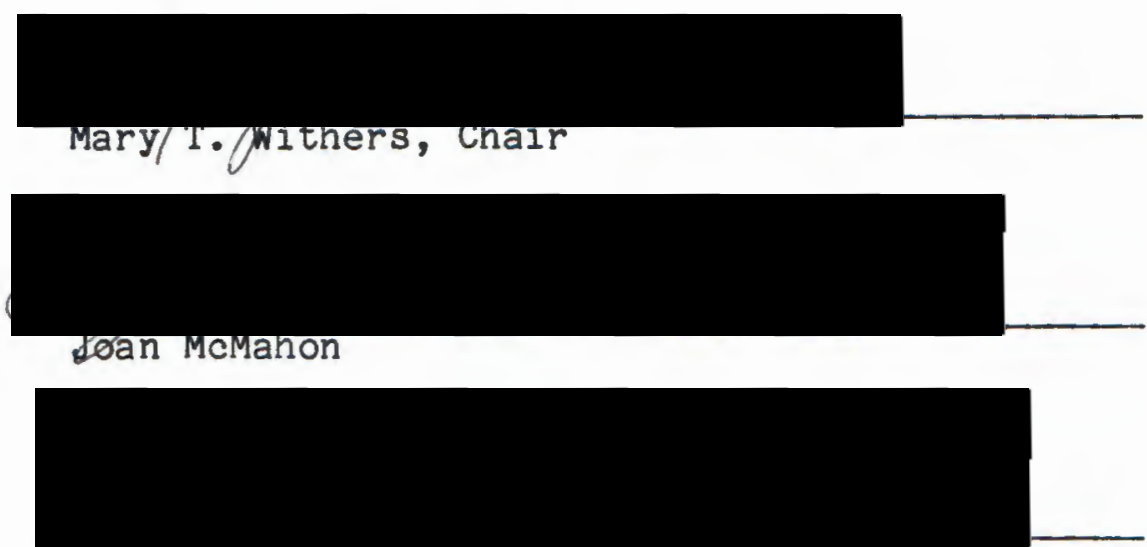

kooert w. kempIer

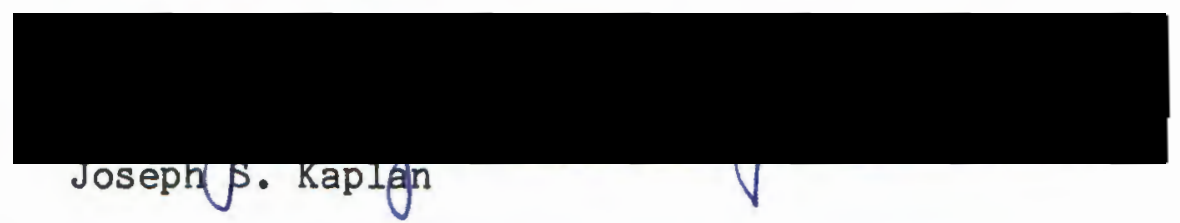

Acoustical analyses have been utilized to ascertain the functional status of the laryngeal mechanism for clinical management of communication disorders (Gilbert and Weismer, 1974). In particular, the modal frequency level (MFL), defined as the fundamental frequency most of ten used by an individual in 
the act of spontaneous speech (Travis, 1971), is one measurement used to determine if a person's pitch level is adequate. Two other pitch measurements used in the voice assessment are the maximum frequency range (MFR) and the optimum pitch level (OPL). Information is needed to provide guidelines for pitch levels as part of the voice evaluation for adult females of different ages. It is not clear from the literature if there is a statistically significant MFL difference between White female nonsmokers and cigarette smokers as determined by different phonatory tasks. The purpose of this investigation was to compare the MFLs of nonsmoking and cigarette smoking White females between the ages of forty and fifty years. The primary research question was: Does smoking significantly affect the modal frequency level of forty to fifty year old White females as compared with forty to fifty year old White females who do not smoke?

The ancillary questions to be answered are:

1. Does the amount of smoking affect the fundamental frequency of women?

2. Is the modal frequency level significantly different when measured during three separate phonatory tasks? Sixty-two subjects, consisting of twenty-four White female nonsmokers and thirty-eight white female cigarette smokers, between the ages of forty and fifty years participated in this investigation. The thirty-eight smokers were divided into two groups, designated Groups $A$ and $B$, eighteen and twenty in each respectively, according to the amount of cigarettes they smoked. 
Groups A subjects smoked twenty to 29 cigarettes per day and Group B subjects smoked 30+ cigarettes per day. A nonsmoker was defined as a person who has never smoked.

All subjects indicated no past or present history of voice disorders. The experimenter judged the voice quality of each subject. Every participant in this investigation had normal hearing, no marked foreign accent and no formal training or experience in public speaking or singing. They reported no colds, sore throats, allergies, post-nasal drip or sinus infection at the time of testing. No vocal abuse was noted within the last forty-eight hours. Subjects were chosen from several occupational groups. Menopausal status information was self reported during subject interviews.

The subjects were audio recorded, completing three phonatory tasks. Each produced a two minute speech sample and read the middle 55 words of the "Rainbow Passage" (Fairbanks, 1960) and three vowels sustained 5 seconds each. The collected data was analyzed by a Visi-Pitch frequency analyzer and statistically computed on an Apple IIc computer using a SwyftWare program.

Results from this investigation revealed statistically significant differences obtained from spontaneous speech, oral reading and vowel phonatory tasks between nonsmokers and smokers and between Groups $A$ and $B$ smokers. In examining the resulting data from this study, it was concluded: 
1. Smoking did significantly affect the MFL of females in this investigation. Numerical values were lower for the smoking population than for the nonsmoking population when compared in all three phonatory tasks, with differences ranging from $8.7 \mathrm{~Hz}$ to $13.2 \mathrm{~Hz}$.

2. The amount of smoking does affect the fundamental frequency of women. Group B smokers ( $30+$ cigarettes) had significantly lower modal frequency levels than Group A smokers (20 - 29 cigarettes). These results agree with those of Sorensen and Horii (1982) who suggest that the more heavily a person smoked the greater the change in voice characteristics for female smokers.

3. The MFL was significantly different between the three phonatory tasks comparing the nonsmoking and smoking population. Speech values were lower than reading, with comparative differences ranging from $2.9 \mathrm{~Hz}$ to $5.9 \mathrm{~Hz}$, and in agreement with the investigations of Hudson and Holbrook (1982) and Sorensen and Horii (1982). Vowel values were different when compared with reading and speech, ranging from $14.3 \mathrm{~Hz}$ to $24.9 \mathrm{~Hz}$. Results are in agreement with the study by Sorensen and Horii (1982).

To determine if there were systematic changes in MFLs as a function of age, subjects were divided into two groups on a basis of age. The 45 to 50 year old group had lower values than the 40 to 44 year old group for reading and speech, except for nonsmokers and Group A. 
COMPARISON OF THE MODAL FREQUENCY LEVELS OF NONSMOKING AND CIGARETTE SMOKING WHITE FEMALES BETWEEN THE AGES OF FORTY AND FIFTY YEARS

by

JANIS MAE KAUFMAN

A thesis submitted in partial fulfillment of the requirements for the degree of

MASTER OF SCIENCE

SPEECH COMMUNICATION:

SPEECH AND HEARING SCIENCES

Portland State University

1991 
TO THE OFFICE OF GRADUATE STUDIES:

The members of the Committe approve the thesis of Janis Mae Kaufman presented November 29, 1990.

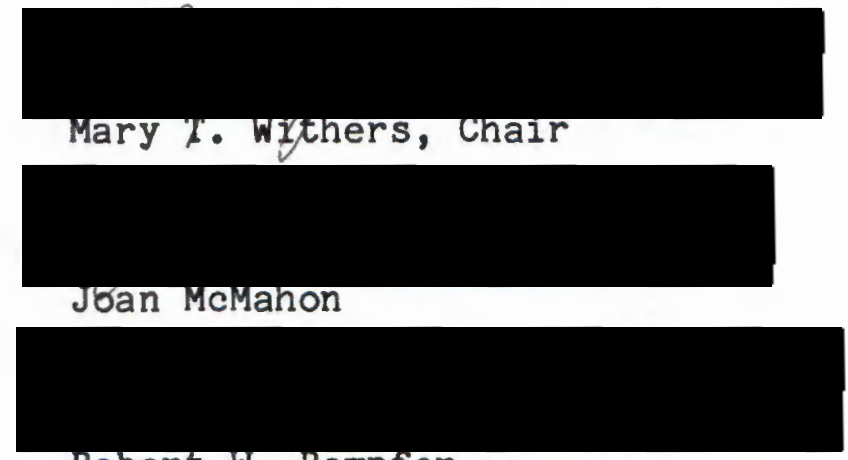

Robert w. Rempier

$$
\text { Joseph S. Kagplan }
$$

APPROVED :

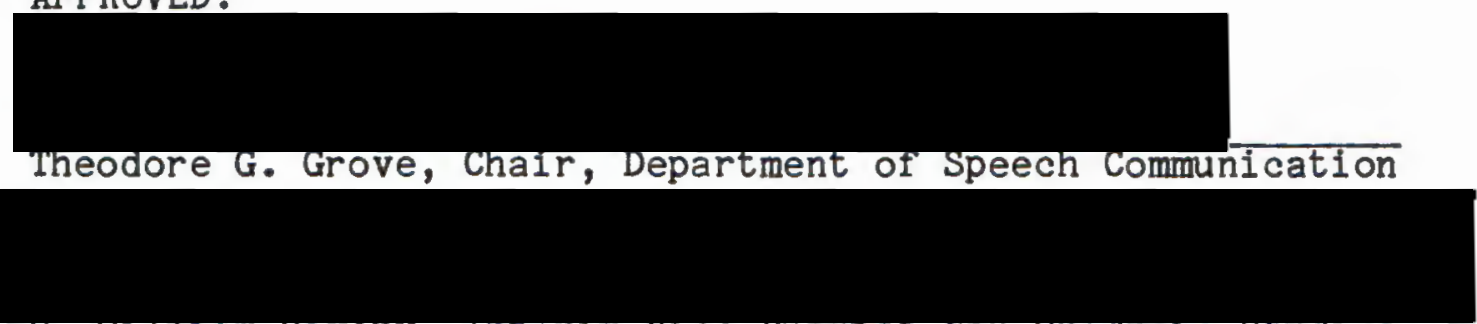
C. wIIItaw Savery, Interim vice Prowost Ior Graduate stuales
and Research 
TABLE OF CONTENTS

PAGE

LIST OF TABLES............................ v

CHAPTER

I INTRODUCTION $\ldots \ldots \ldots \ldots \ldots \ldots \ldots \ldots \ldots \ldots \ldots \ldots \ldots$

Statement of Purpose.................. 3

Operational Definitions................ 4

II REVIEW OF THE LITERATURE................ 6

Pitch as a Voice Characteristic........... 7

Pitch Parameters.................... 8

Anatomy, Physiology and Age: Its Affect on MFL. 9

Anatomy and Physiology................. 9

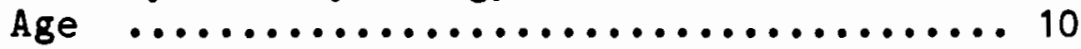

Pitch Disorders....................... 10

High Pitch......................... 11

Low Pitch.............................. 11

Limited Pitch Range....................13

Voice Evaluation...................... 13

Maximum Frequency Range................ 14

Optimum Pitch Level.................... 14

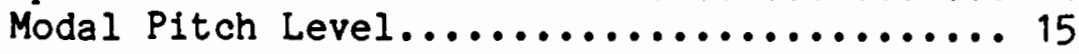

Research Concerming MFL of Female Adults...... 16

MFL of Normal Adult Females............. 16

MFL of Female Adults who Smoke........... 20

III METHODS AND PROCEDURES.................. 25

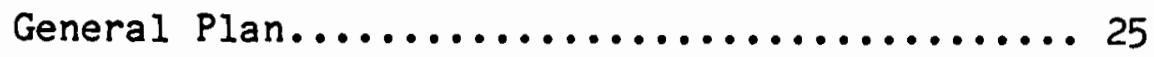




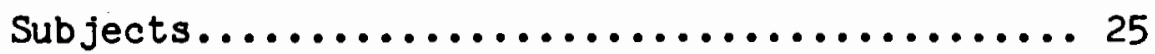

Subject Eligibility................ 26

Task Settings....................... 27

Phonatory Procedures....................... 27

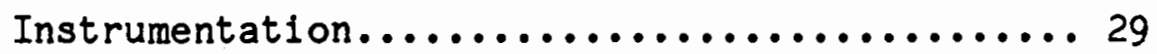

Analyzing Voice Normalcy............... 30

Modal Frequency Analysis..................... 31

Task Analysis Procedures.................. 31

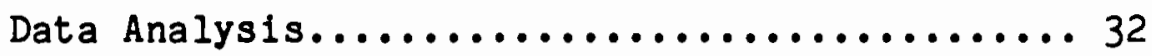

IV RESULTS AND DISCUSSION................. 33

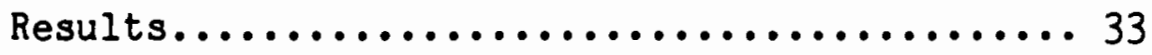

Group Comparisons........................ 34

Discussion.......................... 42

Modal Frequency Levels.............. 42

v SUMMARY AND IMPLICATIONS............... 49

Summary.......................... 49

Implications...................... 52

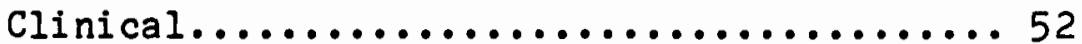

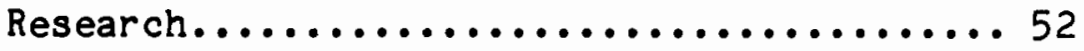

REFERENCES.................................... 54

APPENDICES

A INFORMED CONSENT...................... 58

B SUBJECT ELIGIBILTY SCREENING............. 59

C THE JEWISH HOSPITAL VOICE PROFILE...........6 60

D RAINBOW PASSAGE...................... 61 


\section{LIST OF TABLES}

TABLE

PAGE

I Summary of Previous Research on the Speaking Fundamental of Adult Females.

II Mean Fo Values for Females by Age Group in

Oral Reading, Spontaneous Speech, and Vowels...... 21

II Modal Frequency Levels by Group, Means, Group

Difference and Range From Highest to Lowest

Value $(\mathrm{Hz})$.

IV Comparison of Mean MFL Reported in $\mathrm{Hz} \ldots \ldots \ldots \ldots$

V Mean MFL for Vowels by Population and Comparison

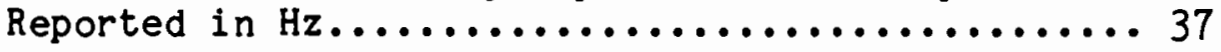

VI Mean MFL Values for Female Smokers and Nonsmokers by Age Group in Oral Reading and Spontaneous speech..................................4 41

VII Menopausal Data on 40 to 50 Year Old Females and the Mean MFLs by Classification for a Reading Task.................................... 44

VIII Comparison of Studies on the Mean MFL of Adult Females... 


\section{CHAPTER I}

\section{INTRODUCTION}

Authorities in the field of speech-language pathology have stressed the importance of measuring the maximum frequency range (MFR), modal frequency level (MFL) and the optimum pitch level (OPL) when diagnosing a voice client to determine if a client is speaking at an appropriate pitch level (Boone, 1983; Mayer, 1974; Perkins, 1983; Prater and Swift, 1984). The MFL, defined as the fundamental frequency most of ten used by an individual in the act of producing spontaneous speech (Travis, 1971), reading or phonating vowels, is one measurement used to ascertain if a pitch level is adequate. The rationale for this measure is that each individual has his own unique MFL which is appropriate for his age, sex, and vocal mechanism. It has been further recognized that each person has a pitch level where the voice functions most efficiently (Fairbanks, 1960) and where the best voice quality is observed (Darley and Spriestersbach, 1978). This pitch level is often referred to as optimum pitch level (OPL) or natural level. The optimum pitch is determined by the anatomic and physiological characteristics of an individual's laryngeal mechanism. Theoretically, the OPL and MFL should be the same or closely approximate one another for the most effective and efficient vocal performance (Boone, 1983). 
The voice clinician uses relatively simple techniques to assess three various measures of pitch - pitch range, optimal pitch level and modal frequency level. The information derived from each measurement is critical when determining if the client is speaking at a pitch level (MFL) that is optimal. Generally speaking, if the obtained MFL and OPL differ by more than two or more tones, voice treatment should be initiated with the objective of changing the client's habitual pitch level.

Another assessment consideration is to compare whether the client is using an MFL which is normal for his sex and age. Normal modal frequency guidelines relative to a person's age and sex are available in the voice literature.

The literature indicates that the MFL will be lowered as a result of smoking, apparently due to a variety of physiological changes in the vocal structures which occur as a consequence of cigarette smoking (Gilbert and Weismer, 1974; Stoicheff, 1981; and Sorensen and Horil, 1982). Cigarette smoke may cause injury to laryngeal tissues in the form of inflammation and edema which contribute to thickening and deforming of the laryngeal structures. Thus, modal frequency levels of ten are lowered as a result of cigarette smoking.

Guidelines concerning the lowered MFL of people should serve as an aid in the assessment of voice disordered clients who smoke. There have been many studies concerning the affect of smoking on the MFL of men (Hudson and Holbrook, 1981, 1982; Fitch and Holbrook, 1970; Sorensen and Hori1, 1982) but the research 
concerning the MFL of females is limited, confusing, and contradictory (Stoicheff, 1981). Eligibility criteria for the selection of subjects in the studies vary (Fitch and Holbrook, 1970; Linke, 1973; Snidecor, 1951). The number of subjects in studies has been very low ranging in number from six to 27. Additionally, there are few studies which address how MFL is affected by the amount of cigarette smoking. These studies do not necessarily analyze the amount of time smoked as a variable affecting MFL (Gilbert and Weismer, 1974). Furthermore, the number of studies which include the female population, aged thirty to eighty-five and over, is limited to the studies by Gilbert and Weismer (1974), Honjo and Isshiki (1980), McGlone and Hollien (1963), Saxman and Burke (1967), Sorensen and Horii (1982) and Stolcheff (1981).

The modal frequency level also can vary in different settings as well as in different phonatory tasks (Hudson and Holbrook, 1982; Sorensen and Hori1, 1982). Because there are various tasks the clinician uses to assess the MFL such as spontaneous and elicited conversation, reading, and/or sustaining specific vowel sounds, comparisons were made to determine if MFL differs according to the phonatory task.

\section{STATEMENT OF PURPOSE}

The purpose of this investigation is to compare the modal frequency levels of nonsmoking and clgarette smoking in white females between forty and fifty years of age. The primary 
question is: Does smoking significantly affect the modal frequency level of forty to fifty year old White females as compared to forty to fifty year old White females who do not smoke? The secondary questions to be answered are:

1. Does the amount of smoking affect the fundamental frequency level?

2. Is the modal frequency level significantly different when measured during three separate phonatory tasks?

\section{OPERATIONAL DEFINITIONS}

Fundamental Frequency $\left(F_{0}\right)$ - The fundamental frequency of the human voice is a one-to-one relationship with the rate of vocal fold vibration which is expressed in cycles per second (Hz), and is the physical correlate to pitch. Hertz (Hz) - a unit of frequency, equal to one cycle per second (c.p.s.) named after H.R. Hertz, German physicist (1857-94) and commonly used to measure pitch.

Maximum Frequency Range (MFR) - a range of frequencies whose quality does not change from the lowest to the highest note in that particular range: 1) glottal fry which includes the lowest range of frequencies, 2) modal which includes the middle range of frequencies normally used in speaking and,

3) falsetto which includes the highest range of frequencies. Modal Frequency Level (MFL) - the most frequently occurring fundamental frequency or pitch used by an individual during 
the act of spontaneous speech. Habitual Frequency Level is another commonly used term to refer to MFL (Travis, 1971). Optimal or Optimum Pitch Level - the pitch level at which the voice is produced most efficiently, with the least amount of laryngeal tension, and with the greatest ease of physical effort (Perkins, 1983).

Pitch - the sound level that is perceived by the human ear as it relates to the frequency of vibration of the vocal folds. Phonation - production of voiced sound waves which result from vocal fold vibration. 
CHAPTER II

REVIEW OF THE LITERATURE

The speech-language pathologist has training in clinical management and in research methodology relative to disorders of voice. There is increasing emphasis on scientific precision by studying the physiology of voice production and the acoustical properties of the volce. By using modern instrumentation, speech-language pathologists have identified and measured the specific vocal characteristics and properties which contribute to volce disorders. These measurements provide necessary information for the proper diagnosis and remediation of volce disorders.

Limited studies have investigated the effects of smoking as it relates to voice disorders and more specifically how it affects the pitch of women who smoke (Gilbert and Weismer, 1974; Sorensen and Horii, 1982). This chapter will focus on literature regarding the pitch levels of women who smoke and those who do not and includes information concerning this topic by discussing the concept of pitch, how pitch is affected by anatomy and physiology, the causes of pitch disorders, and how pitch parameters are analyzed during a voice evaluation. 
PITCH AS A VOICE CHARACTERISTIC

Each individual speaks with a voice that is unique in terms of pitch, loudness, and quality depending on their age, sex, and cultural group. This implies that there are children's voices, adult voices, and male and female voices. It further indicates that there is a normal pitch, loudness, and quality for each group as perceived by the listener.

The concept of "pitch" is recognized as we listen to how low or high an individual's voice appears. As casual listeners, a judgment can be made whether someone is speaking at too high or too low of a pitch level. The pitch of the vocal sound is directly related to the frequency of vibration of the vocal folds. The frequency of vibration is technically referred to as the fundamental frequency $\left(F_{0}\right)$. The terms "pitch" and "frequency" are often used interchangeably. Pitch, however, is the psychological perception that we perceive from the act of the vocal folds vibrating (Hanley and Thurman, 1962). We may say that a pitch is too high or too low. Frequency, on the other hand, is the actual number of cycles per second that the vocal folds vibrate and is expressed in terms of Hertz ( $\mathrm{Hz})$.

In order to more easily understand the value of $\mathrm{Hz}$ as it relates to the highs and lows of pitch, a musical scale standard reference was created comparing notes on the piano to equivalent frequency values. The lowest musical note on the piano was given 
the name $A_{0}$ and $a \mathrm{~Hz}$ of 28 , while the highest note on the piano is $\mathrm{C}_{8}$ or a Hz of 4,186 (Zemlin, 1981).

\section{PITCH PARAMETERS}

The three basic pitch parameters which are critical indicators of proper volce production are: 1) Modal Frequency Level, 2) Optimum Pitch Level, and 3) Maximum Frequency Range. Modal Frequency Level, defined as the fundamental frequency most of ten used by an individual during spontaneous speech, is the measure which indicates whether the pitch is appropriate for the person's sex and age. Generally, adult men speak at a MFL around $125 \mathrm{~Hz}$ while adult females speak at a MFL around $200 \mathrm{~Hz}$ (Boone, 1983). The Optimum Pitch Level, defined as the pitch level at which the voice is produced most efficiently, with the least amount of laryngeal tension, and with the greatest ease of physical effort (Perkins, 1983), is an indication of whether the person is utilizing his vocal mechanism appropriately. The term Maximum Frequency Range (MFR) is defined as the highest and lowest frequencies an individual can phonate.

There are basically three ranges within the maximum frequency range. The modal range includes the middle range of frequencies normally used in speaking. The glottal fry range refers to the lowest range of frequencies. The falsetto range refers to the highest range of frequencies. Although a normal speaker may drop into vocal fry at the end of sentences or 
phrases, it would be considered abnormal to speak in the vocal fry or falsetto range.

Chambers, 1982, reports the phonational frequency range extends from two to four octaves when referring to untrained and trained singing voices respectively.

An important consideration for pitch evaluation is to differentiate between the term Maximum Frequency Range (MFR) and the range of frequencies used during conversational speech. MFR is a measurement of what an individual is capable of producing while the latter refers to what frequency range the individual is actually using during conversation.

ANATOMY, PHYSIOLOGY AND AGE: ITS AFFECT ON MFL

Anatomy and Physiology

Vocal pitch is a result of vocal fold vibrations. Individual pitch levels are regulated by length, mass and thickness, and degree of tension on the vocal folds (Hollien, 1962; Mayer, 1974; Tortora and Anagnostakos, 1978). As tension increases, the length is increased and tissue mass and elasticity is decreased. Consequently, they vibrate faster, elevating the voice pitch (Boone, 1983; Kahane, 1981; Luchsinger and Arnold, 1965). When muscular tension is relaxed the length is decreased and mass and elasticity are increased, hence, the vibratory cycle is slower and the voice pitch is lowered. Generally, the vocal cords are usually longer and thicker in males than females; therefore, the vibratory cycle is slower and 
the pitch is lower than in women (Tortora and Anagnostakos, 1978).

Age

Generally speaking, children up to the age of puberty speak at similar MFLs which are higher than adults. Studies concerning the modal frequency level of children through adolescence indicate that MFL decreases as age increases (Stoicheff, 1981). During the pubertal period the larynx increases in size for males and females. Males experience a lowering of the fundamental frequency of approximately one octave; whereas females experience a lowering of about two or three notes.

Vocal function is affected by physical changes that occur with the aging process. Bone structures of the laryngeal mechanism ossify and calcify according to Luchsinger and Arnold (1965) and Zemlin (1981). Consequently, flexibility and mobility limit high frequencies and frequency range (Kaplan, 1971; Ptacek, Sander, Mahoney and Jackson, 1966).

\section{PITCH DISORDERS}

Pitches that deviate from optimum may be a contributing factor or a result of a voice disorder or laryngeal pathology. Two etiologic categories of voice disorders are functional and organic. Functional disorder indicates no organic involvement of the vocal folds, but infers faulty use of the larynx (Cooper, 
1971). Organic disorder is related to various physical changes in the structure or function of the larynx. Aberrations in pitch levels are generally produced by changes in vocal fold mass or in vocal fold approximation (Boone, 1983).

Moore (1971) described three types of vocal pitch deviations. One type of vocal pitch deviation is when the pitch is consistently higher than is customarily found among persons of the same age in a particular cultural group. A second type of deviation is when the pitch is inappropriately low. A third type is when the pitch range is limited so that the speaker does not use the full range of high and low pitches that he is capable of producing.

\section{High Pitch}

Some voices will remain high-pitched in the late adolescent and adult male. For example, a man may have a female sounding voice as a result of functional or psychogenic influences (Moore, 1971). Another problem is when a larynx is not developed normally. Boone (1983) reports that an immature larynx which does not grow to the required size may be attributed to a hereditary factor, a general structural retardation or poor gonadal, sexual development. When the vocal folds are abnormally small in size, fast vibrations occur which produces a high pitch.

\section{Low Pitch}

Glottal growths on the vocal folds such as polyps, lesions, and vocal nodules or edema and inflammation add mass on the 
glottal margin which creates a structural asymmetry. Cord thickening may result primarily from vocal abuse and misuse, and secondarily from allergies, post nasal drip, sinusitis, and common colds. Added mass to the vocal folds changes the vibratory characteristics which produces slower and irregular vibratory patterns. Boone (1983) suggested that use of a low pitch may be a major source of a functional volce problem. One such example is a person imitating a low pitched voice of someone they admire. This can result in a voice that is abnormal. An individual problem may develop when a person functionally misuses their vocal mechanism as when they shout or yell for a long time period. This can result in a more serious organic problem.

Hypothyroidism and some forms of pituitary gland malfunction may cause the vocal folds to thicken which results in a low pitched voice that is considered inappropriate to the individual. Virilizing drugs, such as testosterone used in the treatment of uterine cancer, may have irreversible pitch lowering effects for some women. Menopause can cause secretion of androgenic (male) hormones which creates thickening of the glottal membrane, thereby producing a lower MFL level. Increase in the testosterone - estrogen ratio possibly functions as a virilizing agent to alter vocal fold tissue in the post-menopausal population. Retention of body fluids adds mass to the vocal folds which contributes to a decrease in MFL (Gilbert and Weismer, 1974; Honjo and Isshiki, 1980; Stoicheff, 1981). 
Smoking contributes to changes in mass, elasticity or compliance of vocal fold functioning and consequently vocal fold vibratory characteristics are affected (Sorensen and Horii, 1982). The alteration is a thickened and deformed laryngeal structure. The result is increased mass with a slow vibratory pattern and lowering of pitch.

\section{Limited Pitch Range}

The pitch range, or range of frequencies most of ten used during conversation, may be limited or limited by choice which results in a monotone range or lack of a variety of inflections. Generally a limited pitch range is a functional cause because the individual has chosen to use a monotone pitch. When an organic problem arises, as in the case of multiple sclerosis, an individual does not have a choice because the pitch range may be limited from an insult or deterioration of the Central Nervous System.

\section{VOICE EVALUATION}

The otolaryngologist and speech-language pathologist have to work together in assessing voice disorders. The medical doctor assesses the physiology and anatomy of laryngeal functioning; whereas, the speech-language pathologist assesses the vocal functioning. When assessing a pitch disorder, the speechlanguage pathologist assesses MFR, OPL and MFL in a systematic 
manner, generally concentrating on one pitch measurement at a time.

Maximum Frequency Range

The Maximum Frequency Range is generally the first assessment. The individual is asked to sing or hum a tone near the middle of his range and to proceed note by note to the lowest possible tone, excluding glottal fry, and to the highest tone, including falsetto, which is capable of being produced. The lowest and highest notes are identified and matched to a piano, pitch pipe or any other instrument, such as the Visi-Pitch, used for pitch analysis (Prater and Swift, 1984). Counting from the lowest to the highest tone will provide the number of tones in an individual's pitch range. The clinician will then determine if the subject has an extended range of four octaves and greater or restricted range of two octaves or less. The rationale for obtaining the MFR is to determine if the individual is capable of varying frequency levels which are expected of a healthy mechanism.

Optimum Pitch Level

The optimum pitch level is obtained after the MFR has been determined. The optimum pitch level for males is considered to be one-fourth of the way from the bottom of the frequency range and for females one or two notes below the one-fourth level (Boone, 1983; Prater and Swift, 1984). 
A second method employed for establishing the optimum vocal pitch is to request the individual to respond with "uh-huh" as if answering a yes/no question. Both syllables must be uttered at the same pitch level, and is often the individuals's optimum pitch (Prater and Swift, 1984).

A third way of getting the optimum pitch value is by asking the client to produce a yawn followed by a sigh. The relaxed sigh may be considered the optimum pitch level for that client (Prater and Swift, 1984).

\section{Modal Pitch Level}

A speech-language pathologist determines a patient's habitual pitch level by requesting the person to sustain a vowel, read a chosen passage or engage in conversation which is then video or audio taped. The tape recorder is stopped at eight to 10 points in the recording in order to match the patient's pitch level to a pitch pipe or other musical instrument so that a MFL value is obtained. The MFL value is then compared to average MFL guidelines relative to the client's sex and age (Prater and Swift, 1984).

Current technology has improved the methods of pitch evaluation. Available commercially are clinical instruments which have been specifically designed for measuring various components of frequency. The Visi-Pitch is one pitch analysis electronic instrument which provides both a digital display/writeout of frequency and an oscilloscopic display as the 
client speaks into a microphone which is coupled to the instrument. This instrument is useful in assessing MFR, MFL and OPL (Boone, 1983; Prater and Swift, 1984).

\section{RESEARCH CONCERNING MFL OF FEMALE ADULTS}

As stated earlier, each person has his own MFL that is unique, habitual and natural and dependent upon different factors such as age, sex, race, smoking, medication, endocrine changes, occupation, physical, mental or emotional status, stress and environmental factors. The following studies, although limited and inconclusive, provide data concerning the frequency levels of normal speaking females and females who smoke. The provided data is referred to interchangeably as mean fundamental frequency level, median speaking fundamental frequency (SFF) and modal frequency level (MFL). (See Table I).

\section{MFL of Normal Adult Females}

The following studies provide data for female adults. The varying values may have been influenced by subject selection, phonatory task, and/or central tendency and variability with regard to statistical values. Linke (1973) chose twenty-seven college students with voices ranging from inferior to superior who did not have speech or volce disorders. Participants were required to speak with a general American dialect. A mean value of 199.8 for SFF was obtained. Linke suggested a possible 


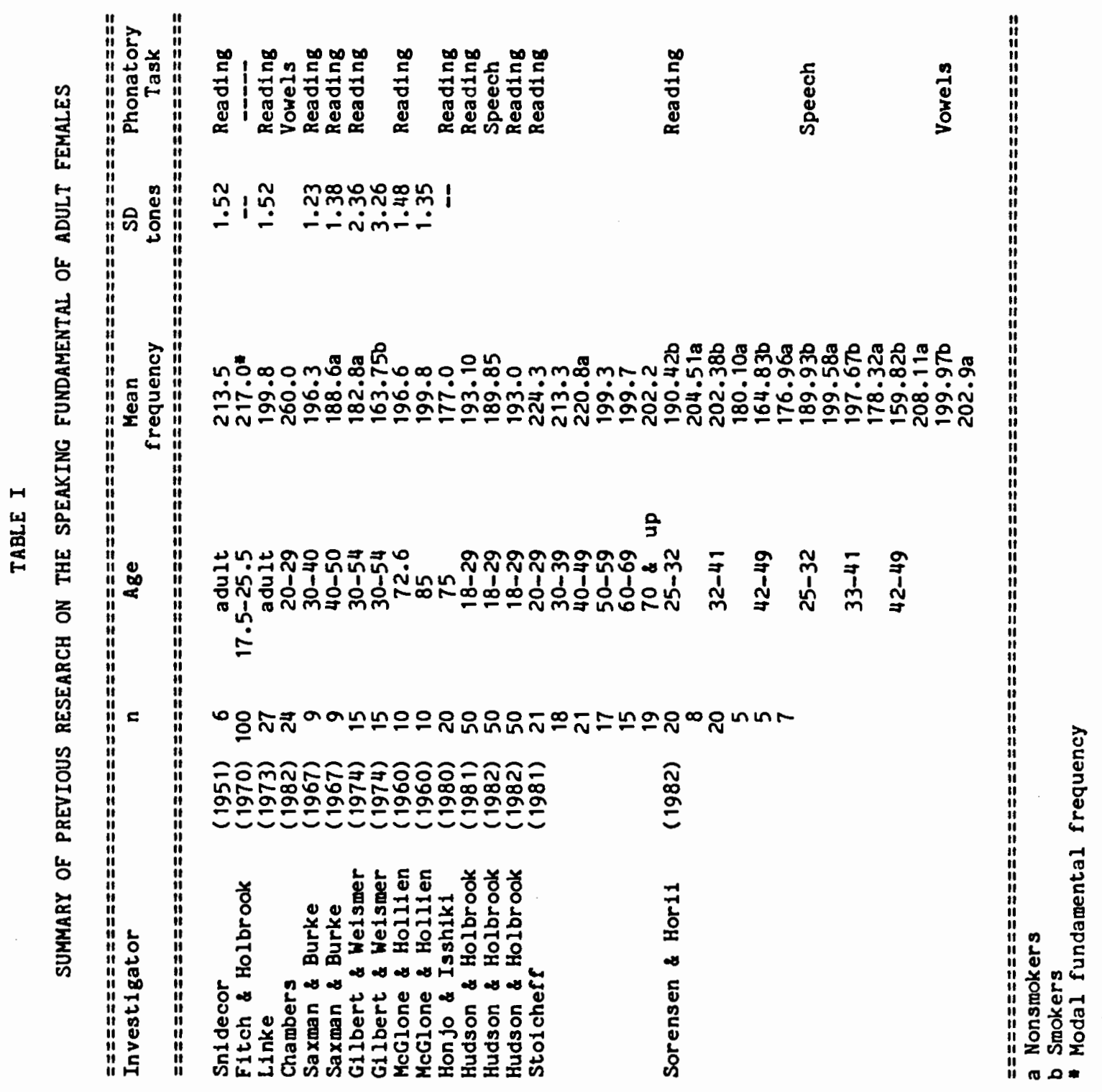


correlation between the effectiveness of the speaking voice and SFF. Ages were not specified.

In Snidecor's (1951) investigation six young female adults with superior speaking voices were selected. Specific ages were not reported, nor was superior defined. If superior meant trained and/or professional, the median SFF value of $213.5 \mathrm{~Hz}$ would have a possible implication of individual control of the vocal mechanism. One hundred university students were selected in the Fitch and Holbrook (1970) research. Ages ranged between 17.5 years and 25.5 years. Speech, hearing and voices were judged to be normal and reading was the phonatory task. The reported FF of $217.0 \mathrm{~Hz}$ was based on individual MFL rather than on the mean $F_{0}(213.5 \mathrm{~Hz})$ as in the studies of Linke (1973) and Snidecor (1951).

Chambers (1982) studied frequency ranges and included FF values for vowels $/ i /, / M /$ and $/ a /$ as the phonatory task. Subjects included 24 women ranging in ages from 20 to 29 years $(M=24.1)$. They had normal hearing and voices within normal limits. For the vowels $/ u /$ and $/ a /$ the natural pitch level was at $\mathrm{B}_{3}$ (musical scale) or $245 \mathrm{~Hz}$ while the natural pitch level for vowel /i/ was $\mathrm{C}_{4}$ (musical scale) or $260 \mathrm{~Hz}$.

Participants in the Hudson and Holbrook (1981) study were 100 males/100 females selected from university introductory speech classes. Subjects were young Black adults ranging in ages from 18 to 29 years. This population demonstrated no significant voice, rhythm or hearing disorders, and had no previous formal 
vocal training. The reading passage, analysis procedures and computation values were similar to Fitch and Holbrook (1970). The mean modal $F_{0}$ for Black females was $193.10 \mathrm{~Hz}$ as compared to $217.0 \mathrm{~Hz}$ for White females in the Fitch and Holbrook (1970) study. The Black population had a lower mean modal $F_{0^{\circ}}$ This information contributes important racial vocal behavior clues to identification of the speaker.

Hudson and Holbrook (1982) investigated the mean SFF in Black female and male subjects using both reading and prompted speech phonatory tasks. Range of ages, central tendency, referring to means and medians, plus dispersion values which include mean range and standard deviations, subject eligibility criteria and data analysis were duplicated from their 1981 study. The mean SFF for spontaneous speech was $189.9 \mathrm{~Hz}$ and reading was $193.0 \mathrm{~Hz}$ for women. Results of this study indicate speaker modes to be higher for reading than for speaking in young Black female adults and are similar to previous study results for white female subjects. The Black population in this study had a lower $F_{0}$ in comparison to published values for young white adult subjects. Hudson and Holbrook (1982), in review of the literature for their study, reported that only four research investigations dealt with reading versus speaking fundamental frequencies (Hudson and Holbrook, 1982, p. 25).

The trend for SFF to decrease from early adulthood through "middle age" was supported in the study by Saxman and Burke (1967). Nine normal speaking women in the 30 to 40 year group 
$(M=33.6)$ had a SFF mean value of $196.3 \mathrm{~Hz}$; whereas, nine normal speaking women in the 40 to 50 year group $(M=44.4)$ had a SFF mean value of $188.6 \mathrm{~Hz}$.

\section{MFL of Female Adults Who Smoke}

Gilbert and Weismer (1974) investigated thirty women ranging in age from 30 to 54 years. In the reading task, fifteen nonsmokers had a higher SFF than fifteen smokers (182.8 $\mathrm{Hz}$ and $163.75 \mathrm{~Hz}$, respectively). An otolaryngologist examined the smokers and found that $87 \%$ exhibited some abnormality of the vocal folds. Results also suggest that menopause may have contributed to lower SFF in females, in addition to smoking.

Sorensen and Horii (1982) investigated 40 normal speaking adult females ranging in ages from 25.1 to 46.8 years $(M=34.9)$, who had smoked from 4 to 30.0 years $(M=13.7$ years). There were 20 smokers in one group and 20 nonsmokers in another group. Subjects had normal hearing. A nonsmoker was defined as an individual who had never smoked or who had not smoked for the last five consecutive years prior to this study. Mean $F_{0}$ values for smoking and nonsmoking females by age group in oral reading and spontaneous speech are indicated in Table II.

Subject data did not reach significant differences in oral reading and spontaneous speech. Smokers had lower $F_{0}$ values except for Group II (age 33 - 41 years) which was based on a population of two. If more subjects had been included the reverse effect may have been possible showing the same trend as 
the remaining cells. The same trends that appeared in oral reading and spontaneous speech were evident in statistical vowel analysis.

\section{TABLE II}

MEAN F。 VALUES FOR FEMALES BY AGE GROUP IN ORAL READING, SPONTANEOUS SPEECH, AND VOWELS

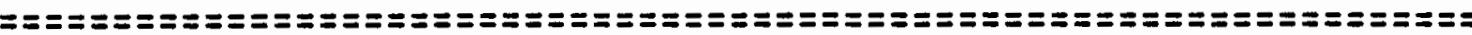
Group I
Group II
Group III
$(25-32$ yrs.)
$(33$ - 41 yrs.)
$(42$ - 49 yrs.)

Reading:

Smokers

190.42

(N: 13)

Nonsmokers

204.51

(N: 8)

202.38

(N: 2)

180.10

83

(N: 5)

(N: 5)

176.96

(N: 7)

Speech:

Smokers

189.93

197.67

159.82

Nonsmokers

199.58

178.32

208.11

Vowels :

/i/

la/

/u/

Smokers

203.50

195.45

200.85

Nonsmokers

205.50

198.75

204.60

Source: Sorensen and Hori1, 1982: pages 139 and 140 .

Consideration should be given to age differences and the distribution of the subjects within the age group plus length of time smoked when comparing statistical values. It is possible that female smokers modified their laryngeal behavior to compensate for low FF's because, in our society, Iow-pitched 
voices are considered to be unfeminine. This possibility could be investigated through electromyography (EMG) patterns.

Stoicheff (1981) investigated SFF's of one hundred eleven nonsmoking female adults ranging in age from twenty to 82 years divided into 6 different groups. Participants were selected from several occupational groups (secretaries, students, housewives, etc.). Subject eligibility included no volce, speech or hearing disorders, no previous formal vocal training, or speaking with a foreign accent which might influence prosody. Subjects had never smoked or had stopped smoking 15 years prior to this study. Menopausal data was obtained (self reports) from all participants prior to participation. Reading was the phonatory task used. Measures of central tendency and of dispersion were obtained. In the Stoicheff (1981) study 15 women, 60-69 years of age, had a MFL of $199.7 \mathrm{~Hz}$ and 19 women, 70+ years of age, revealed a value of $202.2 \mathrm{~Hz}$. The smoking variable in this study was controlled which may account for higher SFF relative to previous studies using adult females. McGlone and Hollien (1963) however, report a value of $196.6 \mathrm{~Hz}$ for 10 females $(M=72.6$ years) and a value of $199.8 \mathrm{~Hz}$ for 10 women ( $M=85.0$ years) for SFF's. Participants were free from significant voice disorders and hearing was normal. In the reading task their ability to read was adequate for age.

The endocrine changes associated with menopause might alter tissue structure of the vocal folds; hence, contributing to a lowering of the $F_{0}$ (Gilbert and Weismer, 1974). If the tissue 
structure alteration contributes to increased vocal fold mass then a decreased $F_{0}$ could be the result, with slight hoarseness evident in aged women (Honjo and Isshiki, 1980). In the Stoicheff (1981) study, data suggests it is menopause completion that affects SFF lowering, not chronological age. Lowered SFF in the 50 year old group is related to the completion of menopause by more women in this group than in the 40 year old age group. In the same study, results indicate an increase in the variablity of the $F_{0}$ in post-menopausal females, inferring some reduced control over $\mathrm{F}_{\mathrm{o}}$ adjustments.

Honjo and Isshiki (1980) obtained a SFF value of $177.0 \mathrm{~Hz}$ on 20 females ranging in ages from 69 to 85 ( $M=75$ years). Laryngoscopic examination revealed edema (increased mass) of the vocal folds in $74 \%$ of the participants which was attributed to general endocrine change after menopause.

Reviewing the data on the studies by Chambers (1982), Gilbert and Weismer (1974), Fitch and Holbrook (1970), Honjo and Isshiki (1980), Hudson and Holbrook (1981, 1982), Linke (1973), McGlone and Hollien (1963), Saxman and Burke (1967), Snidecor (1951), Sorensen and Horii (1982) and Stoicheff 1981), this examiner noted that not all researchers reported information concerning the subject's menopausal history, smoking or nonsmoking, hearing status, voice and speech condition, vocal training, medication, race, age, occupation, and laryngeal condition; nor did they all require the subjects to complete the same phonatory tasks. Subject eligibility criteria varied in the 
different investigations. Only in the normative study by Sorensen and Horil (1982) were the subjects required to complete three phonatory tasks of vowels, reading and speech as well as report their smoking status. Chambers (1982) reported vowel information as part of her investigation and Hudson and Holbrook (1982) reported speech, reading and race. Stoicheff (1981) reported menopausal information, smoking status, health condition and vocal training. Gilbert and Weismer (1974) reported smoking status and Honjo and Isshiki (1980) reported each subject's laryngeal condition because laryngoscopic examinations were performed. Because the information concerning thirty to 50 year old female smokers and nonsmokers is limited to Gilbert and Weismer (1974), Saxman and Burke (1967) and Stoicheff (1981) this examiner chose to investigate the effect of cigarette smoking on SFF in White adult females 40 to 50 years of age and compare them to nonsmokers in White adult females 40 to 50 years of age. 
CHAPTER IV

RESULTS AND DISCUSSION

RESULTS

The purpose of this investigation was to determine the modal frequency levels (MFL) of nonsmoking and cigarette smoking White females between 40 - 50 years of age. This investigation sought to answer whether smoking significantly affects the modal frequency level of forty to fifty year old White females as compared to forty to fifty year old White females who do not smoke. Secondly, this investigation divided the smoking group into two groups, Group A (18) and Group B (20). The groups were selected based on the number of cigarettes they smoked to determine if the amount of smoking affects the modal frequency level. In addition to comparing the various groups, the performance of each group was analyzed in three phonatory tasks to determine if the MFL differs significantly when measured during separate tasks.

The first research question asked was: Does smoking significantly affect the modal frequency level of forty to fifty year old White females as compared to forty to fifty year old White females who do no smoke?

Statistical analysis using the Table of Critical Values of "t" for the level of significance revealed that statistically 
has never smoked. All nonsmoking subjects indicated no past or present history of voice disorders. The experimenter judged the voice quality of each subject. All subjects in this investigation had normal hearing, no marked foreign accent, formal training or experience in public speaking or singing, and no history of treated voice disorders. They reported a negative history of colds, sore throats, allergies, post-nasal drip, and sinus infections at the time of testing. No vocal abuse was noted within the last forty-eight hours. Subjects were chosen from several occupational groups.

\section{Subject Eligibility}

After signing the Consent Form (Appendix A), each participant verbally responded to questions from the Eligibility Screening Form (Appendix B). Throughout the interview, the examiner listened to the participant's voice and made a diagnosis concerning normaley relative to criteria on the Jewish Hospital Voice Profile (Wilson, 1971) (Appendix C) and recorded results on the Consent Form. When eligibility requirements for either the nonsmoking group or one of the two smoking groups were met, the participants then passed a pure-tone audiometric screening at an intensity level of $25 \mathrm{~dB} \mathrm{HL}$ for the frequencies 500, 1000, 2000, and $4000 \mathrm{~Hz}$ bilaterally. The Beltone portable audiometer, Model 10-D and TDH air receivers MX-41/AR cushions were employed. 


\section{TASK SETTINGS}

Upon meeting eligibility requirements, the subjects completed the three phonatory tasks in a quiet room with ambient noise level no greater than $40 \mathrm{~dB}$ SPL. The subject sat in a comfortable chair facing the experimenter. The microphone-tomouth distance of about one to one and one-half inches was maintained by each participant. The sound pressure level meter distance from the subject was approximately 36 inches.

Analysis of the modal frequency levels for the three phonatory tasks took place in the Voice Clinic at Portland Center for Hearing and Speech.

\section{PHONATORY PROCEDURES}

Each subject, who had randomly been assigned an identification number, was tape recorded, completing three phonatory tasks. Each produced a spontaneous speech sample for two minutes, read the middle 55 words of the "Rainbow Passage" (Fairbanks, 1960) (Appendix D), and sustained three vowels, /i/, $/ \mathrm{u} /$, and /a/ following carrier phrases, for approximately five seconds for each vowel trial ( 3 of each) using the Jaxon Timer stop watch, No. 3102. To provide a degree of standardization, each subject completed the three tasks in identical sequence with the same instructions. Preceding task \#1, the experimenter identified the subject with a specific identification number. 
Beginning and ending counter numbers on the tape recorder were noted on each subjects' eligibility form.

To obtain a spontaneous speech sample (Task \#1) scenic pictures were placed in front of the subject. The specific instructions for Task \#1 were:

I want you to tell me about the picture or make up a story about the picture. You will be required to talk for two minutes. I will let you know when the two minutes is over. If you run out of things to say, tell me about your family, or tell me about your job. I'll give you some time to think about what you will say. When you're ready, let me know.

In Task $\# 2$, the subjects were required to read the middle 55 words of the "Rainbow Passage." Each participant was instructed to pretend they were reading to a friendly audience. Silent and/or verbal practices preceded the tape recording until the subject felt comfortable and confident.

In the third task, the subjects were instructed to repeat the following carrier phrases and sustain each of the final vowels for about 5 seconds:

1. My friend likes mereeee ( 3 times)

2. I like youuuuuu ( 3 times)

3. Where is your maaaaaa ( 3 times)

Practice in sustaining the vowels was allowed until appropriate phonation with the required intensity level of a 70-80 dB SPL range was maintained. 


\section{INSTRUMENTATION}

The electronic equipment used in this study was the Jaxon Timer, the Ar-Tik Speech and Hearing Tape Recorder, The VisiPitch/IBM Interface Model 6098 compatible computer, the Beltone portable audiometer, and the General Radio Sound Pressure Level Meter. These instruments are described below with specifications.

1. Jaxon Timer No. 3102. An allsport stopwatch that is laser tuned for $1 / 100$ th second accuracy with mode selection and alarm set indicator.

2. Ar-Tik Speech and Hearing Tape Recorder. A specially designed high-fidelity reel-to-reel recorder that operates at a speed of $71 / 2$ ips. Voice productions were recorded on the Ar-Tik.

3. Visi-Pitch, Kay Electronics, Model 608DS/IBM Interface Model 6098 Compatible Computer. An electronic instrument that extracts the vocal fundamental frequency on a cycle-to-cycle basis. The Visi-Pitch provides two oscillographic traces which can be used to track frequency, amplitude or the two together. A digital display of fundamental frequency is included as part of the instrument. For purposes of this study, the following settings were used: Trigger Control/"Normal" button; Range/"B" button; Position/"Fulln button; Function/"Fundamental Frequency" button; Time/"8 
seconds" button. The IBM Interface Model 6098 allows the clinician to display speech and voice characteristics on the screen and statistical calculations provide assessment of client performance.

4. Beltone portable audiometer, Model 10-D. Model TDH-39 air receivers with $M X-41 / A R$ cushions were utilized with the audiometer and assessment of hearing.

5. Sound Pressure Level Meter, General Radio, No 1565B (Type II). Scale A was utilized to measure ambient noise in the test room.

\section{ANALYZING VOICE NORMALCY}

Voice measurements were determined by two evaluators, the investigator of this study and a second scorer, a Speech-Language Pathologist (C.C.C. - SP) with master's degree credentials and fourteen years of professional experience. Both scorers have extensive experience using the Visi-Pitch. The second scorer was uninformed as to the specific eligibility criteria of each subject (Appendix B). She was asked to evaluate volce normalcy prior to using the Visi-Pitch and to record her ratings on a separate form. Inter judge reliability of $90 \%$ between the two evaluators was based on judging voice normalcy. Intrajudge reliability of $90 \%$ was achieved by the author ten days after the initial evaluating session by rating twenty subject recordings. 
MODAL FREQUENCY ANALYSIS

During the first and second tasks, the modal frequency levels were extracted on a cycle-to-cycle basis during the entire middle 8 seconds and recorded on the analysis form. The author determined the sentences to be analyzed for each subject from the spontaneous speech sample and ratings were recorded on the analysis form. The sentence selected from the "Rainbow Passagen to be analyzed for each subject was, "There is, according to legend, a boiling pot of gold at one end." The frequencies were averaged to acquire the mean modal frequency level using the Visi-Pitch. On the third task, the fundamental frequency displayed on the Visi-Pitch during the last four seconds was recorded on the analysis form for the first and last trial of each vowel. The frequencies were added and averaged for each of the 3 vowels to determine the mean modal frequency level for the vowels $/ i /, / u /$ and $/ a /$.

TASK ANALYSIS PROCEDURES

The Ar-Tik Speech and Hearing Recorder, used previously for recording the phonatory tasks, was coupled with the VisiPitch/IBM Interface Model 6098 compatible computer in order to measure the modal frequency levels of each task. 


\section{DATA ANALYSIS}

A completely randomized experiment design (using equal sample sizes) for student t-test was used to determine if a statistically significant difference existed between the modal frequency levels of nonsmokers and smokers in Groups $A$ and $B$, and between the smoking Groups $A$ and $B$ during phonatory tasks: spontaneous speech sample, oral reading and vowels $/ 1 /, / \mathrm{l} /, / \mathrm{a} /$. Data analysis determined the mean of the modal frequency level for each phonatory task of each subject. Level of significance used was determined by the Table of Critical Values of "t." The Apple IIc computer, using a SwyftWare program, was utilized for statistical evaluation. 


\section{CHAPTER III}

\section{METHODS AND PROCEDURES}

\section{GENERAL PLAN}

Upon meeting eligibility requirements, each subject completed three phonatory tasks: producing a spontaneous speech sample, reading a segment of the "Rainbow Passage" (Fairbanks, 1960) and sustaining three vowels following carrier phrases. The data was analyzed to determine the modal frequency level of each client using the Visi-Pitch. A comparison was made between MFL of smokers vs. nonsmokers as well as age and amount of cigarettes smoked.

\section{SUBJECTS}

Sixty-two subjects, consisting of twenty-four White female nonsmokers and thirty-eight White female smokers, between the ages of forty and fifty years ( $M: 45.5)$ participated in this investigation. The thirty-eight smokers (age M:44.4) were divided into two groups, designated Groups $A$ and $B$, eighteen and twenty subjects each, according to the amount of cigarettes they smoked. Group A subjects smoked, on an average, 20 to 29 cigarettes per day; and Group B subjects smoked, on an average, $30+$ cigarettes per day. A nonsmoker is defined as a person who 
significant differences existed between the MFLs of smoking and nonsmoking subjects on all of the three phonatory tasks (reading, spontaneous speech and vowel phonation). Smokers had significantly lower MFLs than nonsmokers. Following is data concerning the two groups under separate tasks as discussed in Tables III, IV and V.

Group Comparisons

Nonsmokers and Smokers for Reading and Speech. For the oral reading phonatory task the 24 nonsmokers had a higher frequency level, with a mean of $186.5 \mathrm{~Hz}$ than for the 38 (combined) smokers, with a mean of $173.9 \mathrm{~Hz}$ with a numerical spread of 12.6 Hz. Spontaneous speech task followed the same pattern with 24 nonsmokers producing a mean of $180.6 \mathrm{~Hz}$ as opposed to 38 smokers with a mean of $169.2 \mathrm{~Hz}$ with a difference of $11.4 \mathrm{~Hz}$. See Tables III and IV.

Nonsmokers and Smokers for Vowels. On the vowel phonatory task, the nonsmoking population had a mean MFL of $211.44 \mathrm{~Hz}$ as compared to the smoking group who had a mean MFL of $198.23 \mathrm{~Hz}$ resulting in a significance level of 10.14 when combining all three vowels. This indicates that smokers have a lower mean MFL than the nonsmoking group by $13.21 \mathrm{~Hz}$. The MFL was lower for the smoking subjects when compared with the nonsmoking subjects for all three vowels, $/ i /, / u /$ and $/ a /$ Statistically slgnificant differences were evident when vowels and mean MFLs were compared for both nonsmoking and smoking populations. See Table V. 
TABLE III

MODAL FREQUENCY LEVELS BY GROUP, MEANS, GROUP DIFFERENCE AND RANGE FROM HIGHEST TO LOWEST VALUE ( $\mathrm{Hz})$

\begin{tabular}{|c|c|c|c|c|c|c|}
\hline $\begin{aligned} N \\
== \\
24\end{aligned}$ & $\begin{array}{l}\text { Population } \\
==:==z==\Rightarrow==\approx= \\
\text { NS }\end{array}$ & $\begin{array}{l}\text { Task } \\
======= \\
\text { Reading } \\
\text { Speech }\end{array}$ & $\begin{array}{c}\ln \mathrm{Hz} \\
======= \\
186.5 \\
180.6\end{array}$ & $\begin{array}{c}======\pi== \\
5.9 \mathrm{~Hz}\end{array}$ & $\begin{aligned} & 1 \\
&=22=2 \\
& 229 \\
& 231\end{aligned}$ & $\begin{array}{l}\text { In } \mathrm{Hz} \\
====== \\
-152 \\
-141\end{array}$ \\
\hline 38 & $\mathrm{~s}$ & $\begin{array}{l}\text { Reading } \\
\text { Speech }\end{array}$ & $\begin{array}{l}173.9 \\
169.2\end{array}$ & $4.75 \mathrm{~Hz}$ & $\begin{array}{l}223 \\
241\end{array}$ & $\begin{array}{l}-142 \\
-143\end{array}$ \\
\hline 20 & Group B & $\begin{array}{l}\text { Reading } \\
\text { Speech }\end{array}$ & $\begin{array}{l}170.4 \\
167.5\end{array}$ & 2.9 & $\begin{array}{l}223 \\
205\end{array}$ & $\begin{array}{l}=151 \\
=141\end{array}$ \\
\hline 18 & Group A & $\begin{array}{l}\text { Reading } \\
\text { Speech }\end{array}$ & $\begin{array}{l}977.8 \\
171.4\end{array}$ & 6.4 & $\begin{array}{l}223 \\
223\end{array}$ & $\begin{array}{l}-151 \\
-151\end{array}$ \\
\hline $\begin{array}{l}24 \\
38\end{array}$ & $\begin{array}{r}\text { NS } \\
\text { S }\end{array}$ & $\begin{array}{l}\text { Reading } \\
\text { Reading }\end{array}$ & $\begin{array}{l}186.5 \\
173.9\end{array}$ & 12.6 & $\begin{array}{l}229 \\
223\end{array}$ & $\begin{array}{l}-152 \\
-142\end{array}$ \\
\hline $\begin{array}{l}24 \\
38\end{array}$ & $\begin{array}{r}\text { NS } \\
\text { S }\end{array}$ & $\begin{array}{l}\text { Speech } \\
\text { Speech }\end{array}$ & $\begin{array}{l}180.6 \\
169.2\end{array}$ & 11.4 & $\begin{array}{l}231 \\
241\end{array}$ & $\begin{array}{l}-141 \\
-143\end{array}$ \\
\hline $\begin{array}{l}18 \\
20\end{array}$ & $\begin{array}{l}S \text { - Group A } \\
S \text { - Group B }\end{array}$ & $\begin{array}{l}\text { Reading } \\
\text { Reading }\end{array}$ & $\begin{array}{l}177.8 \\
170.4\end{array}$ & 7.48 & $\begin{array}{l}223 \\
206\end{array}$ & $\begin{array}{l}-151 \\
-141\end{array}$ \\
\hline $\begin{array}{l}18 \\
20\end{array}$ & $\begin{array}{l}S \text { - Group A } \\
S \text { - Group B }\end{array}$ & $\begin{array}{l}\text { Speech } \\
\text { Speech }\end{array}$ & $\begin{array}{l}171.4 \\
167.5\end{array}$ & 3.9 & $\begin{array}{l}223 \\
206\end{array}$ & $\begin{array}{l}-151 \\
-14 i\end{array}$ \\
\hline $\begin{array}{l}24 \\
20\end{array}$ & $\stackrel{\text { NS }}{S \text { - Group B }}$ & $\begin{array}{l}\text { Reading } \\
\text { Reading }\end{array}$ & $\begin{array}{l}186.5 \\
170.4\end{array}$ & 16.1 & $\begin{array}{l}229 \\
206\end{array}$ & $\begin{array}{l}-152 \\
-149\end{array}$ \\
\hline $\begin{array}{l}24 \\
20\end{array}$ & $\stackrel{\text { HS }}{\text { S - Group B }}$ & $\begin{array}{l}\text { Speech } \\
\text { Speech }\end{array}$ & $\begin{array}{l}180.6 \\
167.5\end{array}$ & 13.1 & $\begin{array}{l}231 \\
206\end{array}$ & $\begin{array}{l}-141 \\
-141\end{array}$ \\
\hline $\begin{array}{l}24 \\
18\end{array}$ & MS - Group A & $\begin{array}{l}\text { Speech } \\
\text { Speech }\end{array}$ & $\begin{array}{l}180.6 \\
171.4\end{array}$ & 9.2 & $\begin{array}{l}231 \\
223\end{array}$ & $\begin{array}{l}-141 \\
-151\end{array}$ \\
\hline $\begin{array}{l}24 \\
18\end{array}$ & 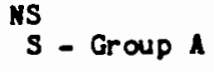 & $\begin{array}{l}\text { Reading } \\
\text { Reading }\end{array}$ & $\begin{array}{l}186.5 \\
177.8\end{array}$ & 8.7 & $\begin{array}{l}227 \\
223\end{array}$ & $\begin{array}{l}-152 \\
-151\end{array}$ \\
\hline
\end{tabular}

NS = Nonsnokers

$S=$ Swokers

Group $A=1.0$ pack or $20-29$ cigarettes per day

Group $\mathrm{B}=1.5+$ packs or 30 or more c1garettes per day 
TABLE IV

COMPARISON OF MEAN MFL REPORTED IN $\mathrm{Hz}$

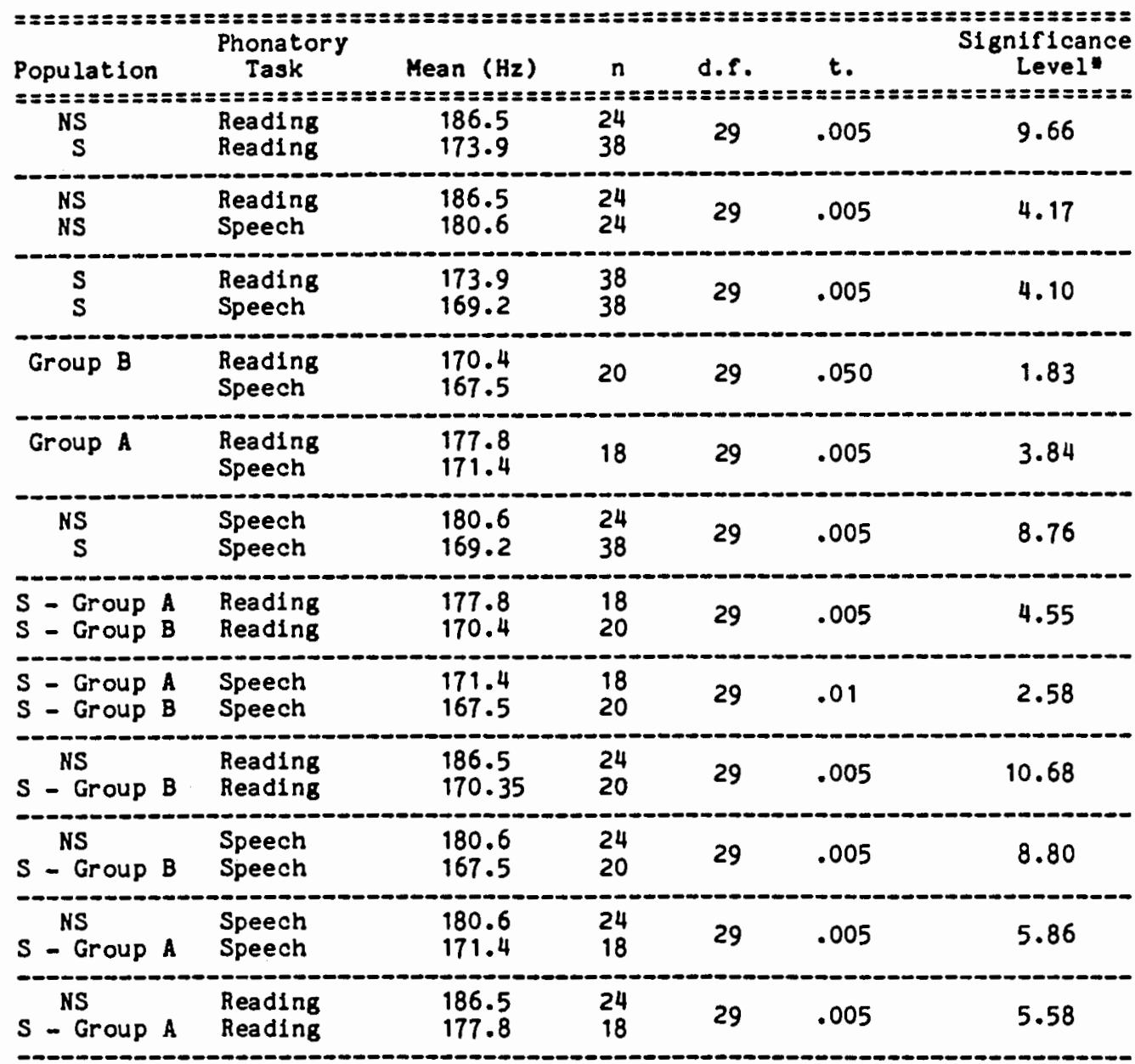

NS $=$ Nonsmokers

$S=$ Smokers

Group $A=1.0$ pack or $20-29$ cigarettes per day

Group $B=1.5+$ packs or 30 or more clgarettes per day

* any number greater than .005 value is signigicant 


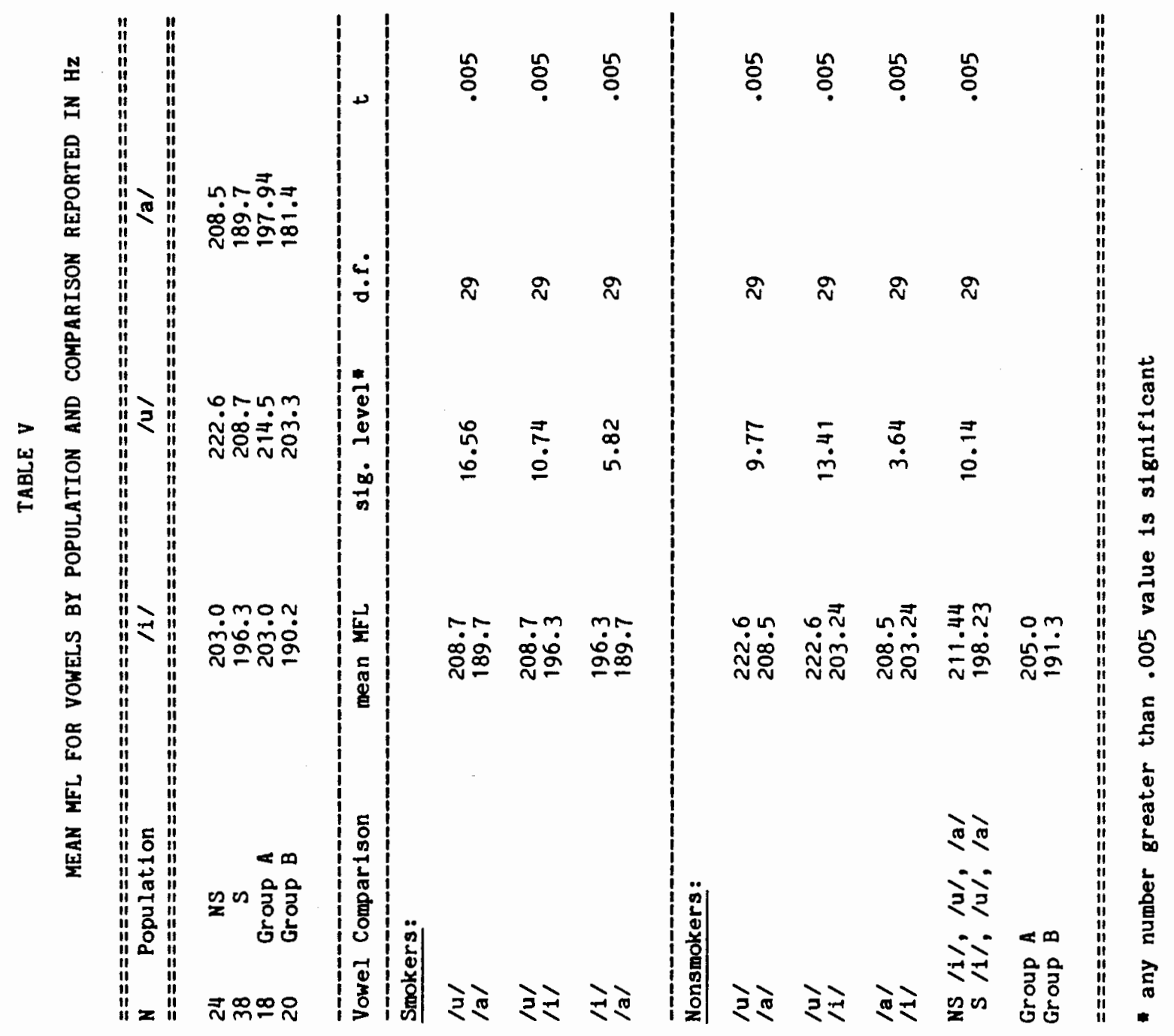


The second question asked was: Does the amount of smoking affect the fundamental frequency level? A summary of the mean MFL values are reported in Tables III, IV and V. The smoking subjects were divided into two groups, one that smoked twenty to 29 cigarettes per day (Group A) and those that smoked thirty or more cigarettes per day (Group B). Overall, Group B subjects had significantly lower MFLs than Group A subjects.

Following is a comparison of the MFL for Groups A and B under separate tasks.

Smoking Groups A and B for Reading and Speech. The twenty subjects in Group B averaged a MFL of $170.4 \mathrm{~Hz}$ (range $206 \mathrm{~Hz}$ to $141 \mathrm{~Hz}$ ) for oral reading; whereas, 18 smokers of Group A averaged a reading MFL of $177.83(223 \mathrm{~Hz}$ to $151 \mathrm{~Hz}$ ) demonstrating that the amount of smoking did affect frequency levels. The difference between the higher value, $177.83 \mathrm{~Hz}$, and the lower value of $170.35 \mathrm{~Hz}$ was $7.48 \mathrm{~Hz}$. Comparing the same population for the spontaneous speech task a MFL average of $167.5 \mathrm{~Hz}$ was cited for Group B and Group A had a frequency value of $171.4 \mathrm{~Hz}$ with a spread value of $3.9 \mathrm{~Hz}$ showing the Group B smokers to have a lower MFL than Group A.

Smoking Groups A and B for Vowels. Group A revealed a mean MFL of $205 \mathrm{~Hz}$ which was $5.87 \mathrm{~Hz}$ higher than Group B's $191.3 \mathrm{~Hz}$ at a significance level of 8.43 .

To further analyze whether the amount of smoking affected MFL, Group $A$ and $B$ were compared to the nonsmoking population in three phonatory tasks. A summary of the means MFL values are 
also reported in Tables III, IV and V. Overall, Groups A and B subjects had significantly lower MFLs than the nonsmoking group with Group B, as previously indicated, having the lowest MFL. Group A and Nonsmokers for Reading. In the statistical review for the reading task 18 Group A subjects had a value of $177.8 \mathrm{~Hz}$ as compared to the 24 nonsmokers' value of 186.5 giving a difference in value of $8.7 \mathrm{~Hz}$. Group A had the lowest statistical value for the reading task.

Group A and Nonsmokers for Speech. After comparing Group A $(\bar{x} 171.4 \mathrm{~Hz}$ ) for the MFL and nonsmokers ( $\bar{x} 180.6 \mathrm{~Hz}$ ) relative to spontaneous speech a difference value of $9.2 \mathrm{~Hz}$ was revealed. The nonsmoking (24) population had a higher mean MFL than the smoking (18) group.

Group B and Nonsmokers for Reading and Speech. For the 20 Group B subjects on the oral reading task the average MFL was $170.4 \mathrm{~Hz}$ as compared with the 24 nonsmokers with an average MFL of $186.5 \mathrm{~Hz}$, with a difference of $16.1 \mathrm{~Hz}$. The nonsmoker category had a higher pitch level for reading and spontaneous speech. Comparing Group B for spontaneous speech resulted in a frequency value of a mean of $167.5 \mathrm{~Hz}$ as compared with 24 nonsmokers for the same phonatory task which provided a numerical value of a mean of $180.6 \mathrm{~Hz}$. The MFL difference was $13.1 \mathrm{~Hz}$. Another question arose from this study and is directly related to the affect that the amount of smoking has on the MFL: Does age significantly affect the fundamental frequency level? 
Nonsmokers and Smokers -- Age. As shown in Table VI, mean MFLs are provided according to population and task for ages 40 to 44 year olds (Group I) and for 45 to 50 year olds (Group II). After comparing the two age groups it was noted that nonsmokers and Group A had higher MFLs in Group II for both tasks. Group B revealed lower MFLs for both tasks in the 45 - 50 year age Group II.

The third question asked was: Is the modal frequency level significantly different when measured during three separate phonatory tasks? Overall the spontaneous speech task produced the lowest MFLs, the reading task produced the second highest MFL values, while the combined vowel task produced the highest MFL values.

As seen in Table III (24) Nonsmokers had a mean MFL of 186.5 $\mathrm{Hz}$ for oral reading (MFL ranged from $229 \mathrm{~Hz}$ to $152 \mathrm{~Hz}$ ) while the mean MFL for spontaneous speech was $180.6 \mathrm{~Hz}$, ranging from $231 \mathrm{~Hz}$ to $141 \mathrm{~Hz}$. The speech task value was $5.9 \mathrm{~Hz}$ lower than the reading frequency level. (38) Smokers had a $\bar{x} 173.9 \mathrm{~Hz}$, range $223 \mathrm{~Hz}$ to $142 \mathrm{MFL}$, relative to the oral reading task as compared with a MFL $\bar{x} 169.2 \mathrm{~Hz}$, range $241 \mathrm{~Hz}$ - $143 \mathrm{~Hz}$ for spontaneous speech providing a difference of $4.75 \mathrm{~Hz}$. As in the nonsmoking group, the smokers had the lowest value for spontaneous speech. Group B smokers had a mean MFL of $170.4 \mathrm{~Hz}$ for oral reading while the mean MFL for spontaneous speech was $167.5 \mathrm{~Hz}$ for a difference of $2.9 \mathrm{~Hz}$ and reading task is the higher value. Group 


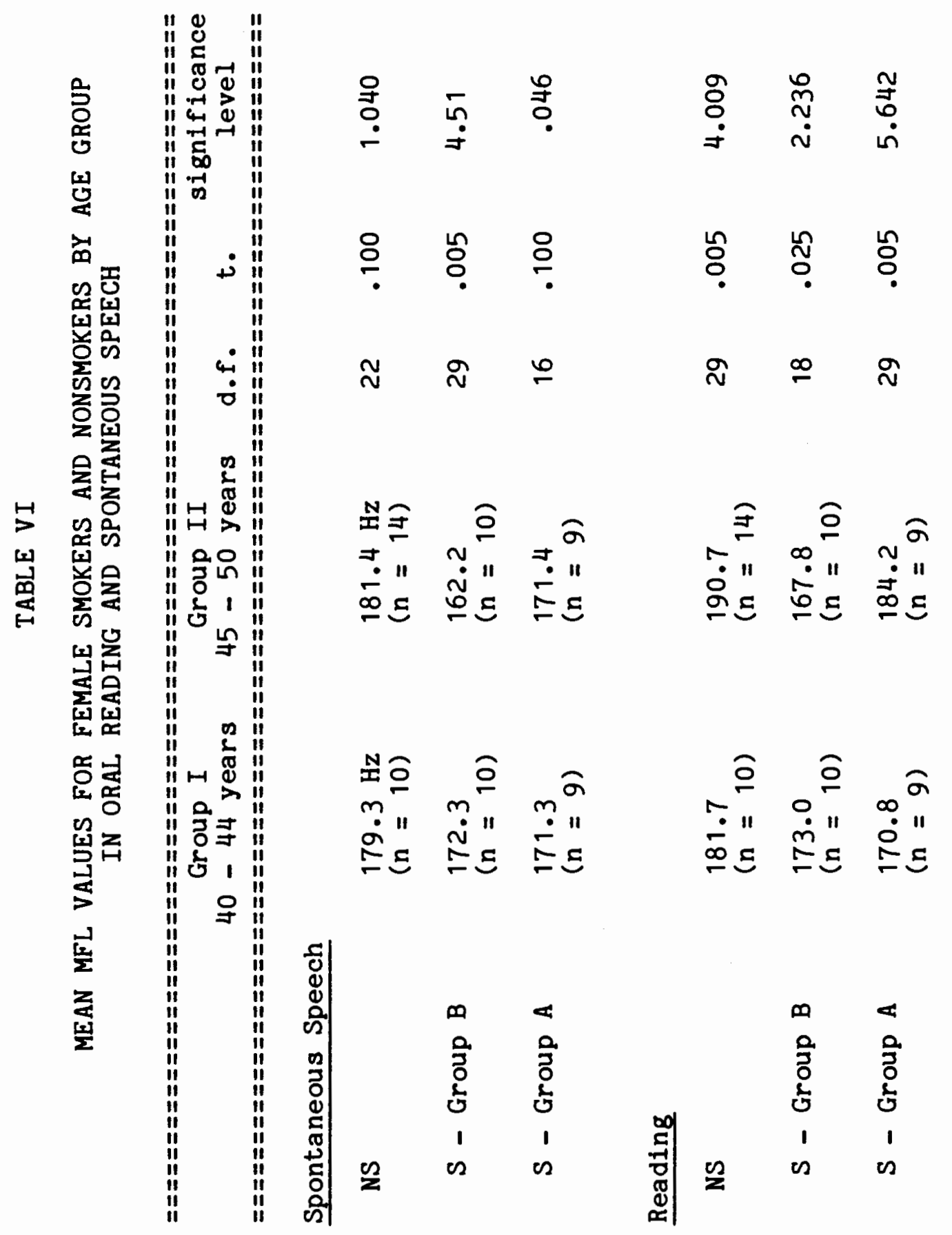

II 
A smokers follow the same trend with a value of $177.8 \mathrm{~Hz}$ for reading and $171.4 \mathrm{~Hz}$ for speech with a difference of $6.4 \mathrm{~Hz}$.

Nonsmokers had a higher value of $211.4 \mathrm{~Hz}$ for the combined vowels /i/, / $/$ / and /a/ as compared with $186.5 \mathrm{~Hz}$ for reading and $180.6 \mathrm{~Hz}$ for speech. Smokers revealed $198.23 \mathrm{~Hz}$ for combined vowels as opposed to $173.9 \mathrm{~Hz}$ for reading and $169.2 \mathrm{~Hz}$ for speech, demonstrating a similar trend.

\section{DISCUSSION}

Modal Frequency Levels

This investigation sought to answer if smoking significantly affects the modal frequency level (MFL) of forty to fifty year old White females who smoke as compared to forty to fifty year old White females who do not smoke. Additionally this study sought to determine MFL values for women relative to the amount they smoke and in three phonatory tasks in order to better evaluate pitch behaviors in women.

Statistical results from this investigation indicate smoking significantly affects the MFL of forty to fifty year old White female smokers and nonsmokers. Combined smokers and Groups A and B individually, had lower mean MFL when compared with the nonsmoking population for the oral reading, spontaneous speech and sustained vowel (combined or individual) phonatory tasks. The data from this study is not in conflict with similar studies, Saxman and Burke (1967); Gilbert and Weismer (1974) and Sorensen and Horii (1982). However, the numerical value of $220.8 \mathrm{~Hz}$ for the 
reading task of the 40 - 49 year age group ( $n: 21)$ in

Stoicheff's (1981) study is in conflict with the present study value of $(n: 24) 186.5 \mathrm{~Hz}$ by a difference of $14.3 \mathrm{~Hz}$. There are several plausible explanations.

One explanation may be related to menopausal status (Gilbert and Weismer, 1974). In both studies menopausal information was collected from all subjects in the form of self reports. Subjects reported current menopausal status, hysterectomy information and hormonal related history. The present investigation revealed statistically significant differences between the smoking subjects for the oral reading task when comparing pre-menopausal $(172.9 \mathrm{~Hz})$ and menopausal $(172.7 \mathrm{~Hz})$ against post-menopausal subjects $(147.5 \mathrm{~Hz})$ for an approximate difference of $5.3 \mathrm{~Hz}$ with the post-menopausal group having a lower MFL mean. The nonsmoking participants, comparing premenopausal $(181.5 \mathrm{~Hz})$ and menopausal (195.5 Hz) status, showed a higher value for the menopausal duration. See Table VII for values.

In the Stoicheff (1981) research study, menopausal data was reported which indicated the SFF in adult females to be consistent until it lowers as a result of menopausal completion. In the forty to 49 year age group the pre-menopausal value was $215.6 \mathrm{~Hz}$, the menopausal value was $219.8 \mathrm{~Hz}$ and the postmenopausal value was $192.9 \mathrm{~Hz}$. Investigations which studied age related changes in the larynx reported information that suggests 


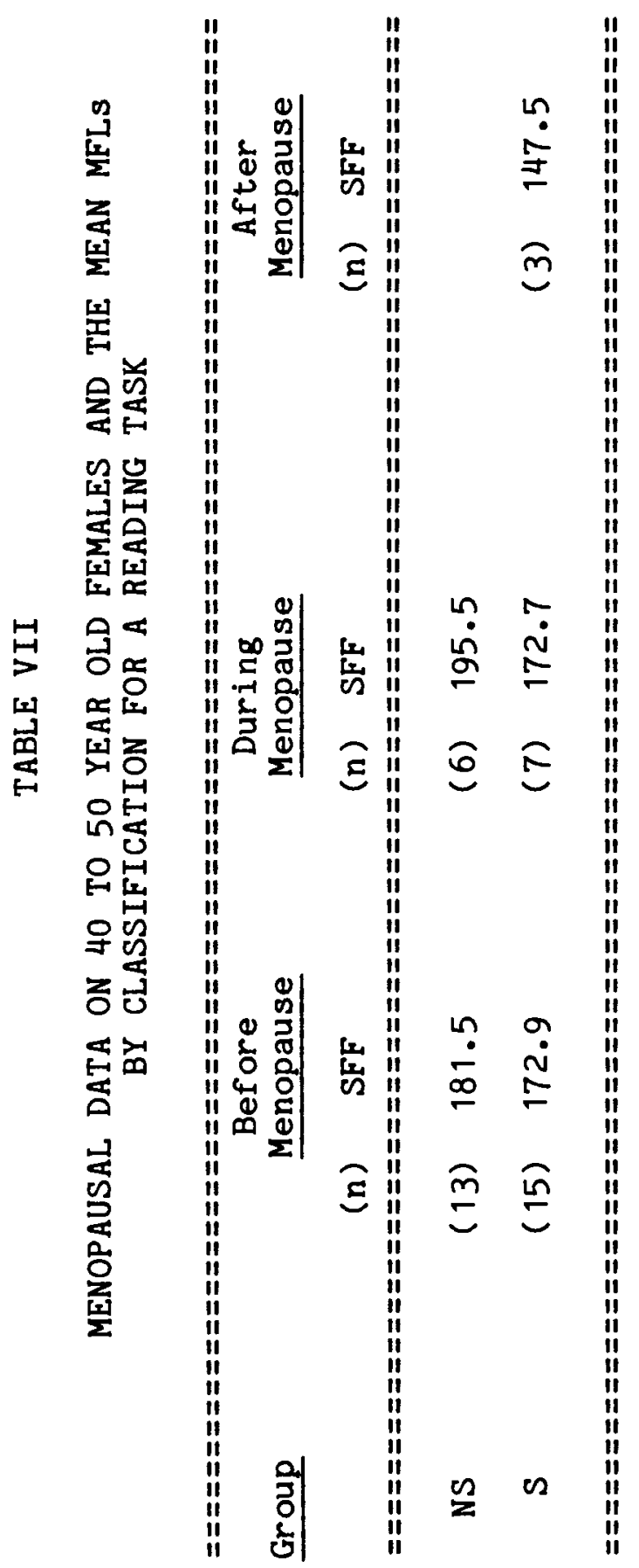


changes in the larynx begin at menopause (Stoicheff, 1981). Possible changes can occur in vocal fold tissue caused by inconsistent variation of the hormonal ratio (testosteroneestrogen) which affects the MFL.

Another consideration to explain the difference between this study's reading task value and Stoicheff's (1981) is that a subject may purposely choose to change their pitch for a variety of reasons (Stoicheff, 1981). Influencing considerations may include pre-conceived ideas, a time factor, attitudes about the task or investigator and/or stress. External influencing factors may include unscheduled interruptions, mechanical problems, unexpected noise or change of task setting.

This study further indicates that the amount of smoking affects the fundamental frequency level. Group B had consistently lower mean MFL than Group A for oral reading, spontaneous and elicited speech, and sustained vowel phonatory tasks, combined and individual. Referring to length of time smoked, Group A had a mean of 24.9 years (12 to 34 year range) as opposed to Group B which had a mean of 26.9 years (15 to 36 year range). Sorensen and Horif (1982) comment on the amount smoked plus length of time smoked to suggest both may damage the vocal mechanism and thus, alterations in vocal characteristics may be more numerous.

Statistical information from this investigation suggests that a significant difference exists between the phonatory tasks values when the nonsmoking and smoking populations were compared. 
Numerical values were lower for the smokers in all tasks. Sorensen and Horil (1982) reported a similar trend which was reflected in their data and is in agreement with the current investigation. See Table VIII for values.

An additional question not posed formally could address the difference in MFL between the two age groups. Sorensen and Horil (1982) divided smokers and nonsmokers into three age subgroups to see if there were "systematic" changes as a function of age for both reading and speech. Smokers had consistently lower numerical values with the exception of the subjects in the 33 to 41 year group. The investigators included only two subjects in this group and suggested that more subjects in this category may have reversed the values. Comparing values in the three age groups for smokers and nonsmokers in both phonatory tasks illustrated a lowering of the MFL as age increases which is in reasonable agreement with this study. In the present investigation for Group B the MFL was lower for the 45 to fifty year age group than for those between forty to 44 years in both the reading and speech tasks. However, Group $A$ in both age categories did not reveal a statistical difference for spontaneous speech. For the oral reading task the 45 to fifty year olds had a higher value than the forty to 44 year old category in Group A. Nonsmokers in both speech and reading tasks had a lower MFL in the forty to 44 year age group. 
$\infty 00000000$

$\infty 00000$

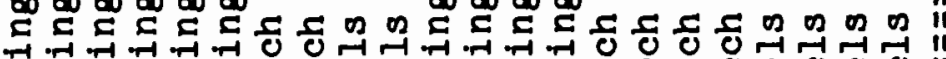

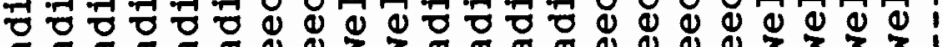
『刃

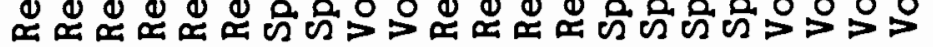

ம $\dot{\infty} \dot{i} \dot{0} \dot{0} \dot{0} \dot{0} \dot{0} \dot{0} \dot{0} \dot{0} \dot{0} \dot{0} \dot{0} \dot{0}$

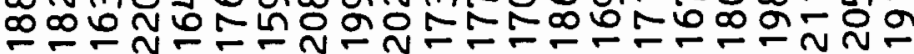

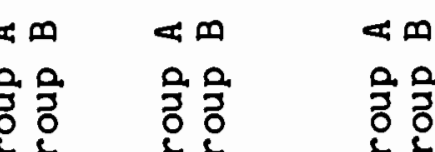
๓ 역 웍

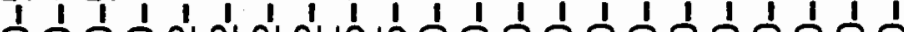

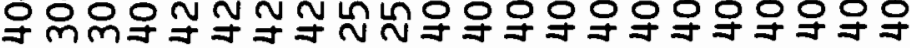

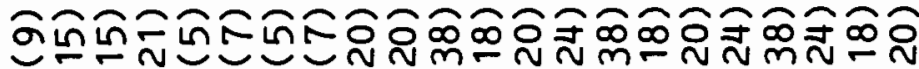

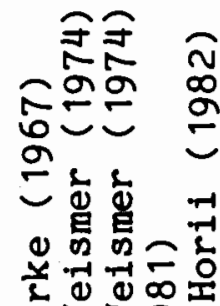

m $\geq$ 再

कृ 0 己

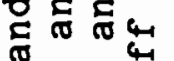

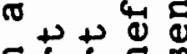

ट

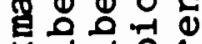

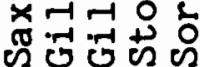

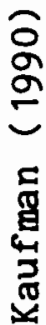

\ֶ.

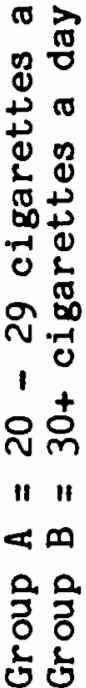


Based on significant statistics from the current study it may be reasonable to speculate that a significant difference does exist between forty to fifty year old White female nonsmokers and smokers, between Group A and B, between Group I and II and between the phonatory tasks when the modal frequency is measured. 


\section{CHAPTER V}

\section{SUMMARY AND IMPLICATIONS}

\section{SUMMARY}

Research investigators have identified and measured the specific vocal characteristics and properties which contribute to voice disorders by using modern instrumentation. Vocal characteristics include modal frequency level (MFL), optimum pitch level (OPL), and/or phonatory range. Assessment of the three vocal characteristics is important in order to ascertain whether or not a person is speaking or singing at an optimum pitch or has a normal range. Frequency measurements are part of the acoustical analysis used to identify whether a person is speaking at an appropriate pitch relative to his age, sex and status of the laryngeal mechanism (Fairbanks, 1960; Gilbert and Weismer, 1974). The purpose of this investigation was to compare the modal frequency levels of nonsmoking and cigarette smoking White females between the ages of forty to fifty years of age. The investigation sought to answer the primary question: Does smoking significantly affect the modal frequency level of forty to fifty year old White females as compared with forty to fifty year old White females who do not smoke?

The secondary questions to be answered are: 
1. Does the amount of smoking affect the fundamental frequency level?

2. Is the modal frequency level significantly different when measured during three separate phonatory tasks? Sixty-two subjects, consisting of twenty-four White female nonsmokers and thirty-eight White female smokers between the ages of forty and fifty years participated in this investigation. The thirty-eight smokers were divided into two groups, designated Group A and B, according to the amount they smoked. Group A subjects (18) smoked, on an average, 20 cigarettes per day and Group B subjects (20) smoked, on an average, 30+ cigarettes per day. A nonsmoker is defined as a person who had never smoked. All subjects in this investigation had normal hearing, no marked foreign accent, formal training or experience in public speaking or singing and no history of treated voice disorders, past or present. The experimenter judged the voice quality of each subject. They reported a negative history of colds, sore throats, allergies, post-nasal drip and sinus infection at the time of testing. No vocal abuse was noted within the last forty-eight hours. Subjects were chosen from several occupational groups.

The subjects produced a two minute spontaneous speech sample, read the middle 55 words of the "Rainbow Passage" (Fairbanks, 1960) and sustained three vowels ( 3 trials each for five seconds). The two phonatory tasks were completed by each participant in identical sequence with the same instructions. 
Spontaneous speech and oral reading were audio-recorded and analyzed by a Visi-Pitch frequency analyzer for exact frequencies.

Study results revealed statistically significant differences existed between MFLs for nonsmoker and smokers, smoker Groups A and B, Groups I and II, by age, and between spontaneous speech, oral reading and sustained vowel phonatory tasks.

A difference does exist between nonsmokers and smokers. The MFLs of the 24 nonsmokers $(186.5 \mathrm{~Hz})$ and 38 combined smokers $(173.9 \mathrm{~Hz})$ were compared with each other in the oral reading task to demonstrate a lower value for the smoking population. The same trend occurred when nonsmokers (180.6 Hz) and smokers (169.2 Hz) were compared in the spontaneous speech task. Sustained vowel phonation was similar with nonsmokers $(211.5 \mathrm{~Hz})$ and smokers (198.2 Hz) values.

The amount of smoking did affect the MFL as seen between Group $B$ and $A$ in reading $(170.3 \mathrm{~Hz}$ and $177.8 \mathrm{~Hz}$ respectively), in speech ( $167.5 \mathrm{~Hz}$ and $171.4 \mathrm{~Hz}$ respectively), and in vowels (191.3 $\mathrm{Hz}$ and $205.0 \mathrm{~Hz}$ respectively). Group $\mathrm{B}$ had consistently lower values which may suggest that the more an individual smoked the lower the MFL.

The MFL is different when measured during three separate phonatory tasks. For all groups, the lowest MFL was produced during spontaneous speech, the second lowest during reading and the highest for the vowel task. 


\section{IMPLICATIONS}

Clinical

Information from this study may be used by speech-language pathologists as reference guidelines to help determine if a pitch disorder exists in female smokers. Since speech-language pathologists use different phonatory tasks to analyze pitch, the MFL guidelines relative to phonatory tasks will be useful. The information concerning MFL may aid in understanding the effects that cigarette smoking has on the laryngeal mechanism and may serve as a reference point to counsel clients regarding the harmful effect of smoking. Also, clients could be warned that the longer they smoke, the lower their MFL will become.

\section{$\underline{\text { Research }}$}

Based on statistically significant differences between 1) White female nonsmokers and smokers, 2) between Group $A$ and Group B smokers, 3) between Group I and II smokers, 4) between vowels and 5) phonatury tasks, further investigation is indicated for comparison for all five categories.

It may be useful to replicate the present investigation using other age groups of smokers and nonsmokers, to determine the relative MFL values according to age. The length of time smoked could be included.

Oral reading, spontaneous speech and sustained vowel production were applied in the Sorensen and Horil (1982) study 
using smokers and nonsmoker as subjects. As in the present study lower fundamental frequencies were found to exist for the smoking population in the phonatory tasks when smokers were compared with nonsmokers. Additional investigation comparing smokers and nonsmokers utilizing three different phonatory tasks would provide further SFF information. Direct endoscopic examination and electomyography (EMG) are recommended for inclusion in research investigations (Gilbert and Weismer, 1974; Honjo and Isshiki, 1980; Sorensen and Horii, 1982).

Hudson and Holbrook (1981, 1982) researched the SFF using Black adult participants between the ages of 18 and 29 years for the oral reading and spontaneous speech phonatory tasks. Hudson and Holbrook (1981, 1982) suggested more research is needed regarding reading and speaking fundamental frequencies for Blacks below 18 and above 30 years of age. Investigation of Black female smokers and nonsmokers of any age would provide meaningful research data. Additional investigations using different races would contribute interesting data of the SFF and knowledge of racial fundamental frequency characteristics. 


\section{REFERENCES}

Auerbach, D., Hammond, E.C., and Garfinkle, L. Histologic changes in the larynx in relation to smoking habits. Cancer, 1970, 25, 92-104.

Boone, D.R. The voice and voice therapy. Englewood Cliffs, New Jersey: Prentice-Ha11, Inc. 1983.

Brackett, I.P. Parameters of voice quality. In Travis, L.E. (Ed.), Handbook of speech pathology and audiology. Englewood Cliff s, New Jersey: Prentice-Hall, Inc., 1971.

Brodnitz, F. Vocal rehabilitation. Rochester, Minnesota: Whiting Press, Inc., 1959.

Chambers, L.R. Phonational frequency ranges in vocally untrained aduits using different cardinal vowels. Master's Thesis, Portland State University, 1982.

Cooper, M. Modern techniques of vocal rehabilitation for functional and organic dysphonia. In Travis, L.E. (Ed.), Handbook of speech pathology and audiology. Englewood Cliff', $\sqrt{e w}$ Jersey: Prentice-Hall, Inc., 1971.

Darley, F.L. and Spriestersbach, D.C. Diagnostic methods in speech methodology. New York: Harper and Row Publishers, 1978.

Duffy, R.J. Fundamental frequency characteristics of adolescent females. Language and Speech, 1970, 13, 14-24.

Fairbanks, G. Voice and articulation drillbook, (2nd ed.). New York: Harper and Row Publishers, 1960.

Fitch, J.L. and Holbrook, A. Modal vocal frequency of young adults. Archives of Otolaryngology, 1970, 92, 379-382.

Gilbert, H.R. and Weismer, G.G. The effects of smoking on the speaking fundamental frequency of adult women. Journal of Psycholinguistic Research, 1974, 3, 225-231.

Hanley, T. and Thurman, W. Developing vocal skills. New York: Holt, Rinehart and Winston, 1962. 
Hollien, H. Vocal fold thickness and fundamental frequency of phonation. Journal of Speech and Hearing Research, 1962, $\underline{5}$, 237-244.

Hollien, H. The registers and ranges of the voice. In Cooper, M. and Cooper, M. (Eds.), Approaches to vocal rehabilitation. Springfield, Illinois: Charles C. Thomas, Publisher, 1977.

Hollien, H., Dew, D., and Phillips, P. Phonational frequency range of adults. Journal of Speech and Hearing Research, $1971,14,755-760$.

Honjo, I. and Isshiki, N. Laryngoscopic and voice characteristics of aged persons. Archives of Otolaryngology, 1980, 106, 149-150.

Hudson, A. and Holbrook, A. A study of the reading fundamental vocal frequency of young black adults. Journal of Speech and Hearing Research, 1981, 24, 197-201.

Hudson, A. and Holbrook, A. Fundamental frequency characteristics of young black adults: Spontaneous speaking and oral reading. Journal of Speech and Hearing Research, $1982,25,25-28$.

Kahane, J.C. Anatomic and physiologic changes in the aging peripheral speech mechanism. In Beasley, D.S. and Davis, G.A. (Eds.), Aging: Communication processes and disorders. New York: Grune and Stratton, 1981.

Kaplan, H.M. Anatomy and physiology of speech. New York: McGraw-Hi $11,1971$.

Linke, C. A study of pitch characteristics of female voices and their relationship to vocal effectiveness. Folia Phoniatrica, 1973, 25, 173-185.

Luchsinger, R. and Arnold, G. Voice-speech-language: Clinical communicology: Its physiology and pathology. Belmont, California: Wadsworth Publishing Company, Inc., 1965.

Mayer, L.V. Fundamentals of Voice and Diction, (5th ed.). Dubuque, Iowa: Wm.C. Brown Company Publishers, 1974.

McGlone, R. and Hollien, H. Vocal pitch characteristics of aged women. Journal of Speech and Hearing Research, 1963, 6, 164- 170 . 
Mendenhall, W. Introduction to probability and statistics. Boston, Massachusetts: Duxbury Press: PWS Publishers, 1983.

Michel, J.R. and Wendahl, R. Correlations of voice productions. In Travis, L.E. (Ed.), Handbook of speech and audiology. Englewood Cliffs, New Jersey: Prentice-Ha11, Inc., 1971.

Michel, J., Hollien, H., and Moore, P. Speaking fundamental characteristics of 15-, 16-, and 17- year-old girls. Language and Speech, 1966, 9 , 46-51.

Moore, G.P. Voice disorders organically based. In Travis, L.E. (Ed.), Handbook of speech pathology and audiology. Englewood Cliff s, New Jersey: Prentice-Hall, Inc., 1971.

Mysak, E.D. Pitch and duration characteristics of older males. Journal of Speech and Hearing Research, 1959, $2,46-54$.

Perkins, W.H. Voice disorders: Current therapy of communication disorders. Perkins, W.H. (Ed.). New York: Thieme-Stratton Inc., 1983.

Prater, T. J. and Swift, R.W. Manual of voice therapy. Austin, Texas: Pro-Ed, Inc., 1984.

Ptacek, P.H., Sander, E.K., Maloney, W., and Jackson, C. Phonatory and Related Changes with Advanced Age. Journal of Speech and Hearing Disorders, 1966, 9, 353-360.

Ryan, R.F., McDonald, J.J., and Keleman, G. Physiology of the larynx. Physiology Review, 1955, 35, 506-554.

Saxman, J. and Burke, E. Speaking fundamental frequency characteristics of middle aged females. Folia Phoniatrica, $1967,19,167-172$.

Snidecor, J.C. The pitch and duration characteristics of superior female speakers during oral reading. Journal of Speech and Hearing Disorders, 1951, 46, 45-46.

Sorensen, D. and Horii, Y. Cigarette smoking and voice fundamental frequency. Journal of Communication, 1982, 15, 135-144.

Stoicheff, M.L. Speaking fundamental frequency characteristics of nonsmoking female adults. Journal of Speech and Hearing Research, 1981, 24, 437-441.

Tortora, G.J. and Anagnostakos, N.P. Principles of anatomy and

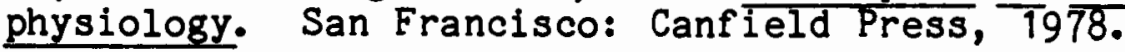


Travis, L.E. Handbook of speech pathology and audiology. Englewood Cliffs, New Jersey: Prentice-Hall, 1971.

Wilson, F.B. The volce-disordered child: A descriptive approach. Language, Speech, and Hearing Services in Schools, 1971, 4,

Zemlin, W.R. Speech and hearing sciences, (2nd ed.). Englewood Cliffs, New Jersey: Prentice-Hall, Inc., 1981. 


\section{APPENDIX A}

\section{INFORMED CONSENT}

$I$, hereby agree to serve as a subject in the research investigation entitled "A Comparison of Modal Frequency Levels of Nonsmoking and Cigarette Smoking White Females, 40-50 Years of Age." This study is being carried out under the supervision of Professor M.T. Withers, Speech and Hearing Sciences Program, Portland State University.

It has been explained to me that the purpose of the study is to learn the effects of cigarette smoking on the larynx (sometimes called the "voice box") and how people talk.

I may not receive any direct benefit from participation in this study, but my participation may help to increase knowledge which may benefit others in the future.

Jan Kaufman has offered to answer any questions I may have about the study and what is required of me in the study. I have been assured that all information I give will be kept confidential and that the identity of all subjects will remain anonymous.

There are no risks or dangers inherent in the procedures of the study. I will have a hearing screening test and participate in several voice tasks by describing a series of pictures for a limited time period, by reading a short passage and by reading carrier phrases and sustaining vowels for limited time periods. I understand that I am free to withdraw from participation in this study at any time.

I have read and understand the foregoing information.

Date Signature

If you experience problems that are the result of your participation in this study, please contact Victor C. Dahl, Office of Gracuate Studies and Research, 105 Neuberger Hall, Portland State University, 229-3423 


\section{APPENDIX B}

\section{SUBJECT ELIGIBLITY SCREENING}

Subject

Counter

Are you a smoker?

Yes No

How old are you? $40, \overline{41,42,43,34} 44,45,46,47,48,44,50$

How many packs (cig.) do you smoke per day |TLAT|T BiITITCi

How long have you smoked? Years Consecutively

Hearing screening

Falled Passed

Volce Description

Foreign Accent

res No

Have you ever smoked?

Ifno....... Yes No

How old are you? $40,41,42,43,44,45,46,47,48,49,50$

How long have you smoked? Years Consecutively

Hearing screening

Falled Passed

Volce normal? Yes No Forelgn Accent? Yes No

\section{Requirements for all subjects:}

1. Have you ever been treated or diagnosed by a physlcian for a vocal problem?

2. Do you have experience or training in public speakin

3. What is your native language?

4. Do you have a cold? sore throat sinusitis post nasal drip allergie (s)

5. Have you strained your volce within the last 48 hours? No Yes spaking or
Nes or

$\begin{array}{ll}\text { Yes } & \text { No } \\ \text { Yes } & \text { No } \\ \text { Yes } & \text { No } \\ \text { Yes } & \text { Nos }\end{array}$
Yes No

\section{Influencing factors:}

1. How long have you 11 ved in this area? Years

2. What is your occupation or profession?

3. Do you drink alcoholic beverages? No

4. Do you experience vocal fatigue or s Days Weeks Months Years

5. Have you started ñenopause?

6. Have you ever had hormone injections?

7. Are you taking any medications: If yes, list which medication and the reason

Months How LOng? Tes How much? 


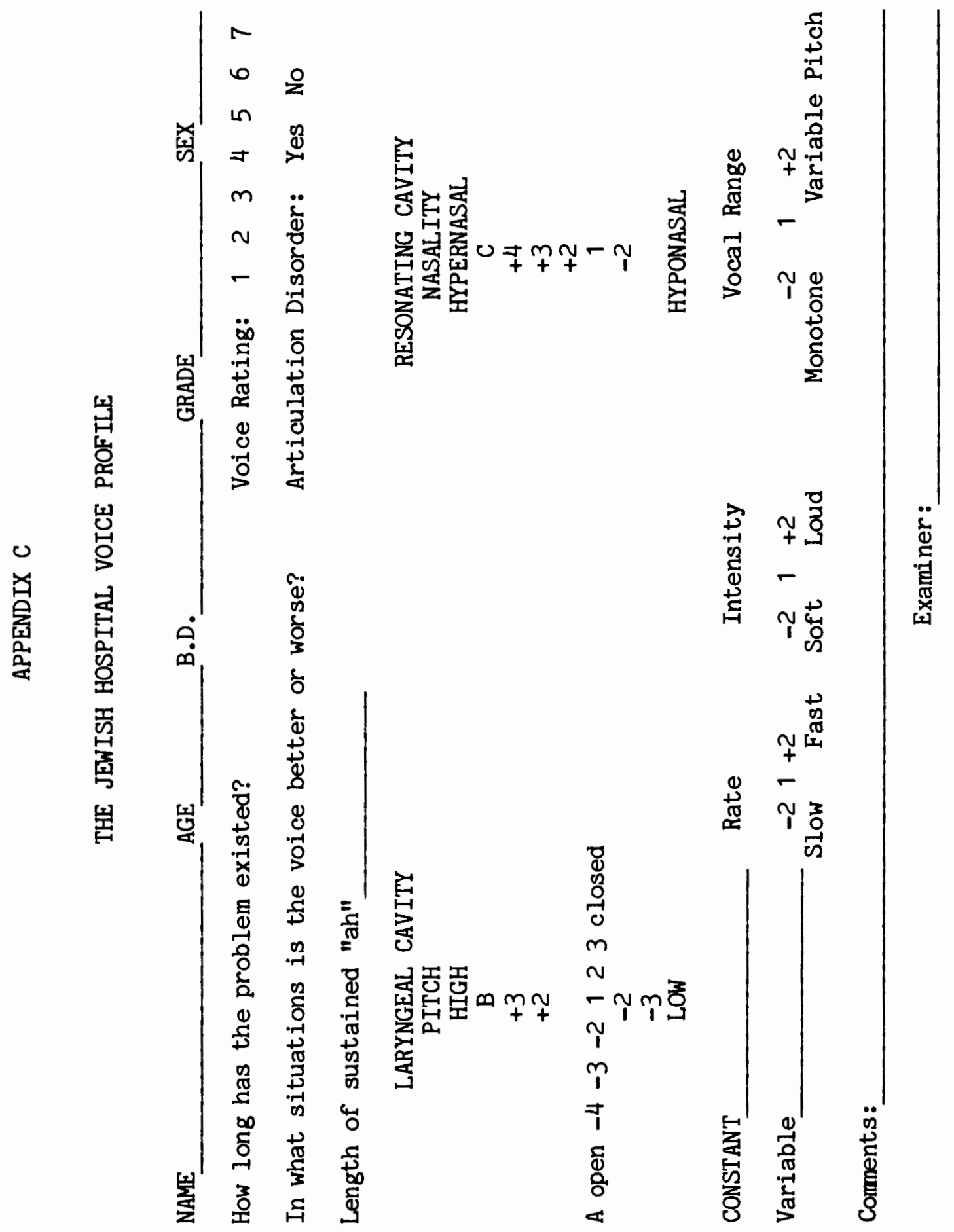


APPENDIX D

\section{RAINBOW PASSAGE}

Paragraph excerpted from: Fairbanks, G., Voice and Articulation Drillbook. New York: Harper and Row (1960).

The rainbow is a division of white light into many beautiful colors. These take the shape of a long round arch, with its path high above, and its two ends apparently beyond the horizon. There is, according to legend, a boiling pot of gold at one end. People look, but no one ever finds it. When a man looks for something beyond his reach, his friends say he is looking for the pot of gold at the end of the rainbow. 